\title{
Precision Postbiotics and Mental Health: the Management of Post-COVID-19 Complications
}

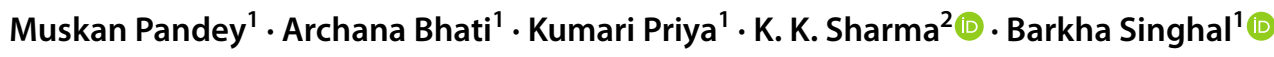 \\ Accepted: 11 November 2021 / Published online: 22 November 2021 \\ (c) The Author(s), under exclusive licence to Springer Science+Business Media, LLC, part of Springer Nature 2021
}

\begin{abstract}
The health catastrophe originated by COVID-19 pandemic construed profound impact on a global scale. However, a plethora of research studies corroborated convincing evidence conferring severity of infection of SARS-CoV-2 with the aberrant gut microbiome that strongly speculated its importance for development of novel therapeutic modalities. The intense exploration of probiotics has been envisaged to promote the healthy growth of the host, and restore intestinal microecological balance through various metabolic and physiological processes. The demystifying effect of probiotics cannot be defied, but there exists a strong skepticism related to their safety and efficacy. Therefore, molecular signature of probiotics termed as "postbiotics" are of paramount importance and there is continuous surge of utilizing postbiotics for enhancing health benefits, but little is explicit about their antiviral effects. Therefore, it is worth considering their prospective role in post-COVID regime that pave the way for exploring the pastoral vistas of postbiotics. Based on previous research investigations, the present article advocates prospective role of postbiotics in alleviating the health burden of viral infections, especially SARS-CoV-2. The article also posits current challenges and proposes a futuristic model describing the concept of "precision postbiotics" for effective therapeutic and preventive interventions that can be used for management of this deadly disease.
\end{abstract}

Keywords Gut microbiome $\cdot$ Probiotics $\cdot$ Postbiotics $\cdot$ Gut-brain axis $\cdot$ Dysbiosis $\cdot$ SARS-CoV-2

\section{Introduction}

The world is facing the apocalypse of egregious pandemic COVID-19 due to SARS-CoV-2 that confers cataclysmic impact on social, economic, and public health at global level. The various respiratory manifestations including sore throat, fever, fatigue, cough, shortness of breath, headache, sputum production, and acute respiratory distress syndrome (ARDS) are an outcome of infection of SARS-CoV-2 [1]. The severity of infection leads to various complications including renal, gastrointestinal, cardiac, neurological symptoms, as well as serving a palette for other chronic secondary fungal and bacterial infections culminating hospitalization and eventually in

Barkha Singhal

barkha@gbu.ac.in

K. K. Sharma

kksharma.microbiology@mdurohtak.ac.in

1 School of Biotechnology, Gautam Buddha University, Greater Noida, Uttar Pradesh 201312, India

2 Department of Microbiology, Maharshi Dayanand University, Rohtak, Haryana 124001, India death [2]. However, these respiratory manifestations accentuated scientific community for bolstering their research in lungs for finding pharmacological and non-pharmacological ailments and most importantly vaccines [3] for combating this problem but the severity of infection has been well correlated with our most dynamic organ of the body, i.e., gastrointestinal tract [4]. The pioneering efforts of various microbiologists present in nineteenth century conceptualize the idea of the presence of microorganisms inside the human body that interplays a constant struggle against each other; however, the advent of next-generation sequencing transformed our understanding towards these microorganisms. Presently, we are living in the era of "rendezvous with our microbes" emboldened the fact that the human body is colonized by trillions of microorganisms and contains approximately 150 million genes that exists in negotiated "state of détente" in symbiotic manner, severely impacting the health and diseased status of humans. This dynamic consortium is referred as "gut microbiome" and the year 2020 portrayed quantum leap on various insights on correlation of gut microbiome with COVID-19 [5, 6]. Research findings evidenced the presence of viral replication in infected human intestinal 
epithelial cells, high expression of ACE-2 receptors in intestinal epithelium, presence of viral RNA in feces, depletion of gut commensals, and enhancement of opportunistic pathogens that highlighted the pivotal role played by gut microbiome in COVID-19 [7-11]. Plenty of research articles have emphasized the intervention of diet, prebiotics, probiotics, and synbiotics that can be used as prophylactic measures for modulation of the gut microbiome [12-16]. Also, scientists are trying to underpin the role of probiotics that can be envisaged in the form of several clinical trials that are still under investigation. Table 1 summarizes the various clinical trials utilizing probiotics for combating COVID-19. Despite the marvelous credentials possessed by probiotics, certain studies indicated their adverse technological and clinical effects including the presence of virulence factors in some probiotic strains, strain-specific mechanisms, diverse patterns of colonization, production of biogenic amines, short lived, ability to cause opportunistic infections, bacteremia and sepsis in immunocompromised individuals, niche-specific action of probiotics (allochthonous or autochthonous), lacking longterm clinical trials, and clear recommendations across the globe [17]. Therefore, the postbiotics, functional bioactive molecules released by probiotics have been thrust area of research nowadays, and there is a growing continuum of studies highlighting the various health benefits that have been reported in the past decade $[18,19]$. However, there is dearth of studies pertaining to the use of postbiotics for antiviral effect especially combating SARS-CoV-2 infections but the past research efforts highlighted the role of postbiotics in ameliorating various viral infections. Thus, based on previous investigations, the article culminates the prospective therapeutic opportunities of postbiotics for coping up the imperil of COVID-19 as well as posits current challenges, and proposes a futuristic roadmap of utilizing the postbiotics in precise manner for overcoming such pandemic situations.

\section{Conception of Postbiotics and Mechanism of Action}

The advancements in elucidating the structural and functional dimensions of gut microbiome lead the world into new era of biotic research. The word "biotics" is derived from the Greek term "biotikós" meaning "pertaining to life" that signify the presence of living organisms in biological ecosystem connected with their physical environment. More comprehensively, the term biotics is more connected towards the adoption of various nutritional strategies that favors the modulation of gut microbiota attaining towards the healthy status of the host [20]. The research has already been directed towards various biotic components like prebiotics, probiotics, and synbiotics and their magnificent ramifications in the host physiology. However, in the quest for interpreting their effects at molecular level in the host, the research has progressed towards understanding the probiotic effector molecules eliciting beneficial response known as postbiotics, the relatively new member of "biotics" family. Postbiotics are considered functional bioactive molecules generated during microbial fermentation of food in gastrointestinal tract. The difference in their effects and composition lies with the extent of microbial metabolization of diverse food matrix; therefore, the term postbiotics is referred as umbrella term for all microbial fermented products and their synonyms [21, 22]. However, several researchers recommended different terminologies to describe probiotic effector molecules like metabiotics, ghost probiotics, inactivated probiotics, non-viable probiotics, paraprobiotics, and pseudoprobiotics [23-25]. Though exact definition has not been described yet, but hitherto postbiotics are defined as non-viable bacterial products or metabolic products from microorganisms that have biological activity in the host [26]. From conception to various applications of postbiotics along with its timeline development is depicted in Fig. 1. The preliminary research highlighted two major classes of postbiotics known as paraprobiotics and fermented infant formulae (FIFs). According to Food and Agriculture Organization/ World Health Organization (FAO/WHO), paraprobiotics is defined as "non-viable microbial cells (either intact or broken) which when administered (either orally or topically) in adequate amounts, confer a benefit on the human or animal consumer" [27], and FIFs are infant or follow-on formula mostly obtained with the fermentation of food by lactic acid-producing microbes and devoid of any viable bacterial cells [28]. Therefore, diversified metabolic products such as short-chain fatty acids (SCFAs), microbial cell fractions, functional proteins, extracellular polysaccharides (EPS), cell lysates, teichoic acid, peptidoglycan-derived muropeptides, and pili-type structures have been categorized as postbiotics. The application of postbiotics alleviates various technical and functional challenges like colonization efficiency, stability and viability in GIT and industrial processing, shelf life, transfer of virulent, and antibiotic resistance genes that are associated with utilization of living cells as probiotics. The credentials of postbiotics such as safe profile, known chemical structures, resistance to hydrolysis, nontoxic, stable to digestive system conditions, and better shelf life confer lucrative options for biotherapeutic utility. Therefore, currently humongous efforts have been made to visualize the application of postbiotics as biotherapeutic agents for the elimination of various diseases. Table 2 summarizes the various applications of postbiotics for maintaining the health status of an individual [29-78]. The current catastrophe imparted due to COVID-19 motivates us to think the prospective role of postbiotics for combating COVID-19 $[79,80]$. However, it is an intriguing fact that there exists an intricate complexity between invasive virus, gastrointestinal 


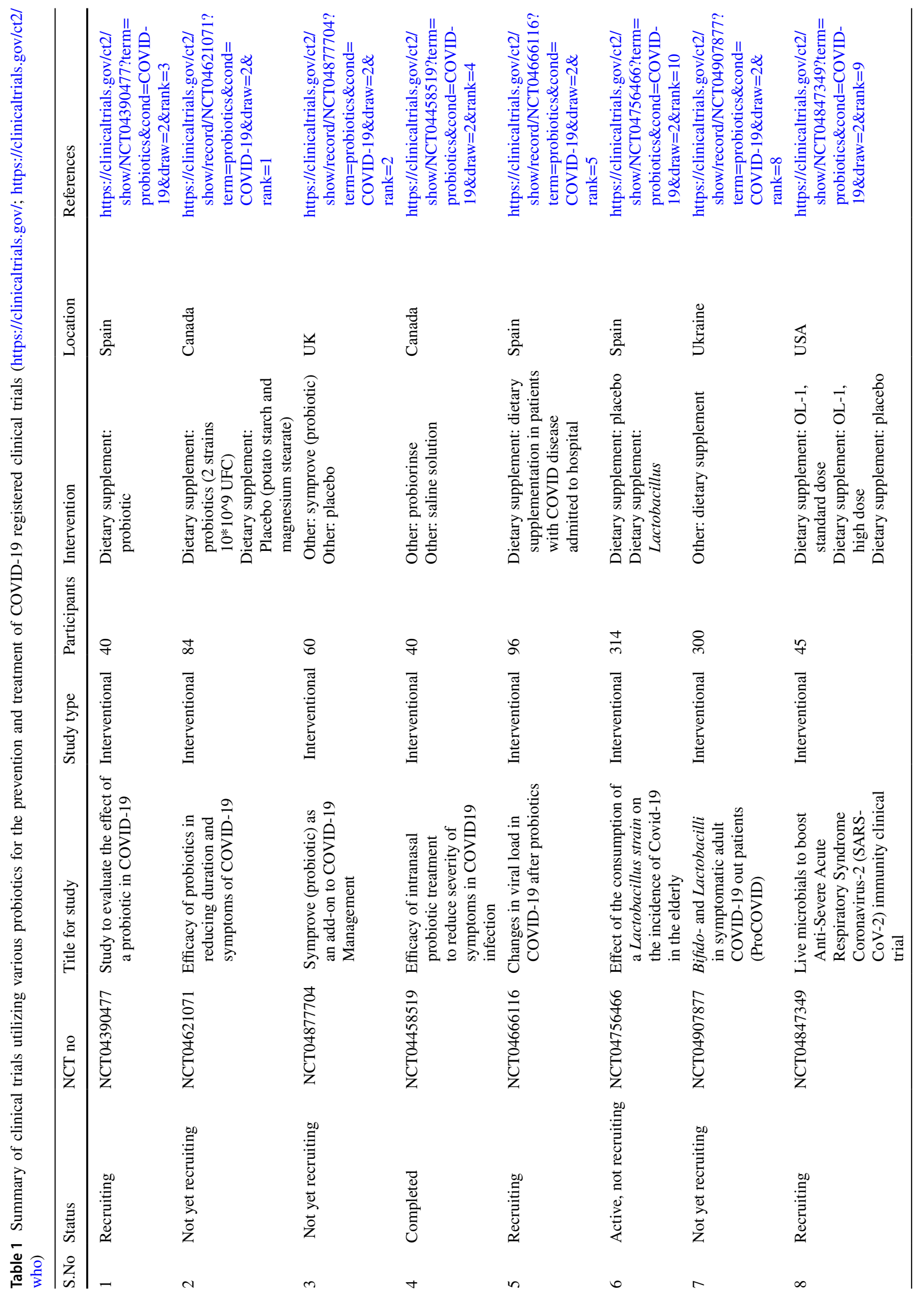




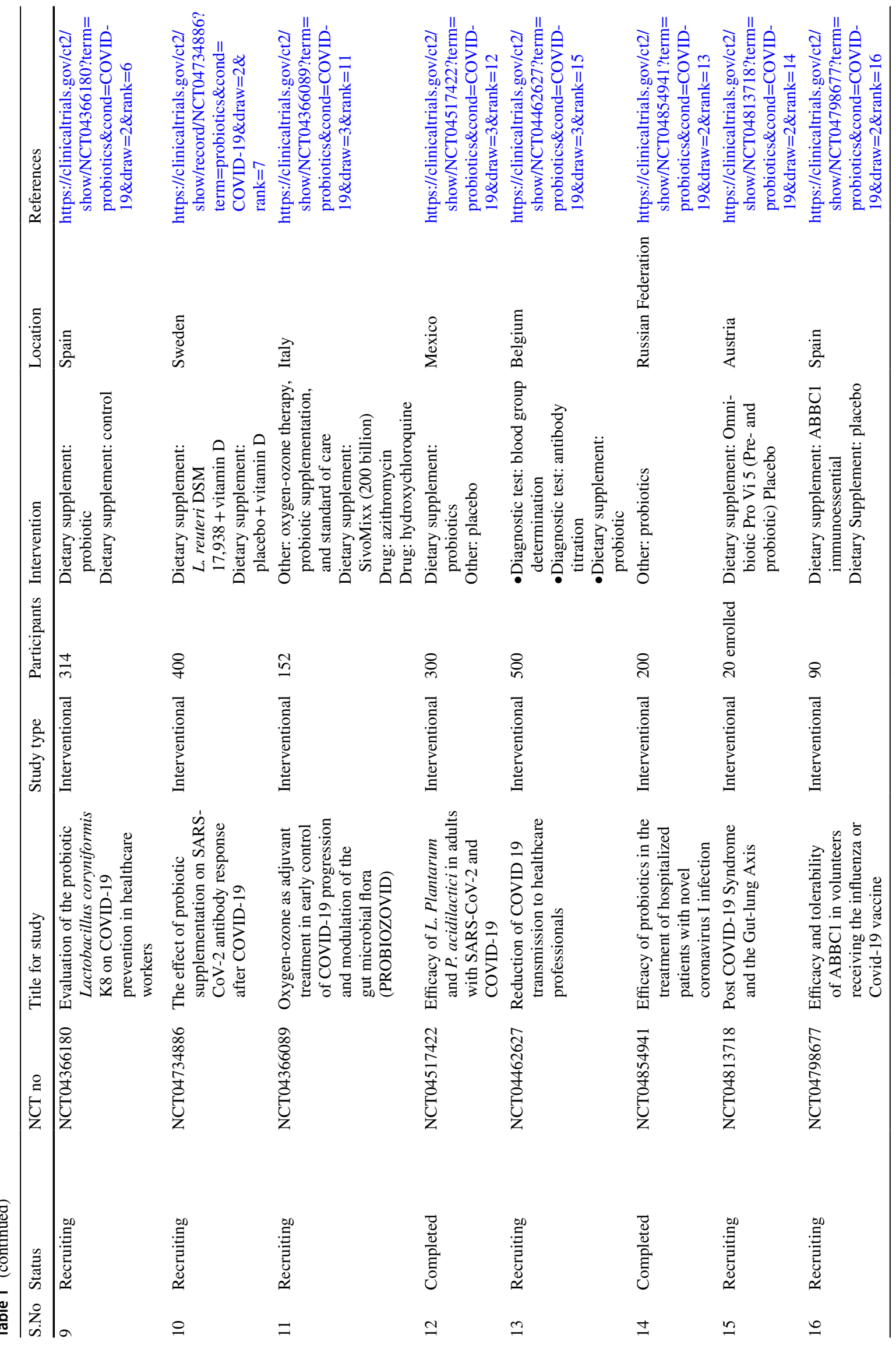




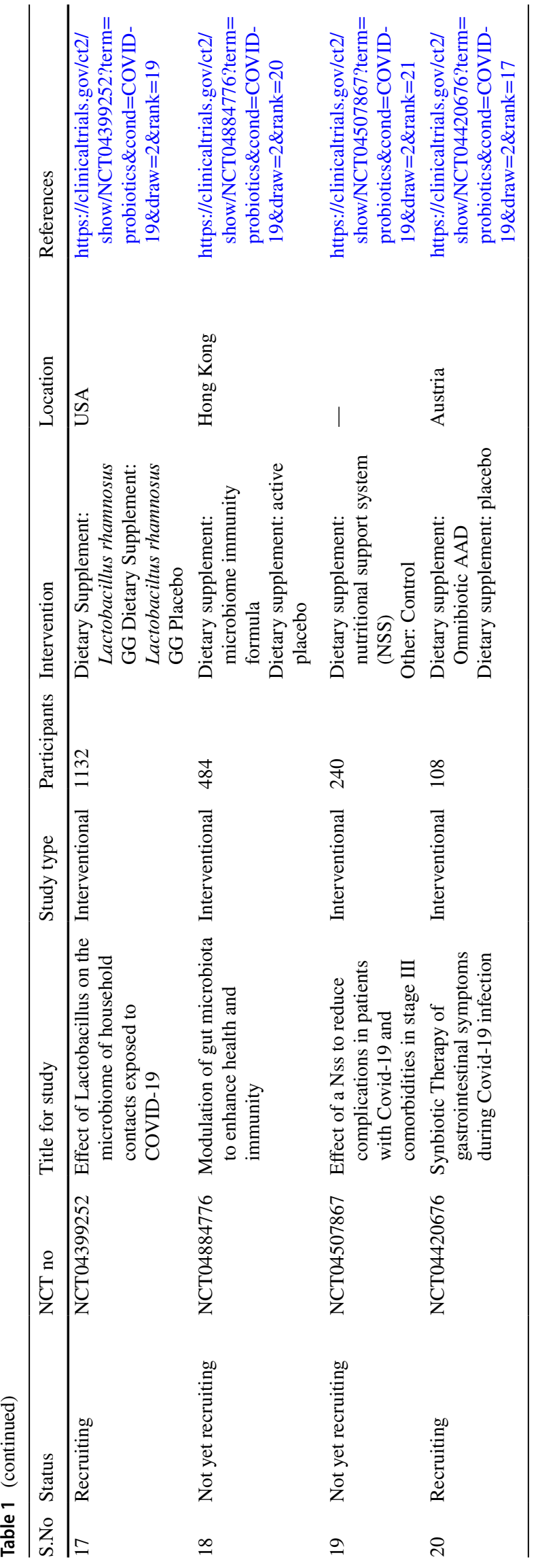

microbiome, and host physiology, but scientists are rigorously trying to unravel these complexities. The antiviral effect of probiotics has been reported in previous studies and based on these research efforts, the antiviral mechanism of postbiotics against COVID-19 can be correlated as (a) production of antiviral inhibitory metabolites, (b) improvement of intestinal epithelial lining barrier function, (c) modulation of innate and adaptive immune system, (d) effect on gutbrain axis, and (e) role in alleviation of secondary fungal infections. The proposed idea of postbiotics triggering various effects that can be a milestone for development of therapeutics for ameliorating COVID-19 needs well-designed clinical trials in humans for further validation and approval for commercial use in the future.

\section{Delineating the Anti-COVID Mechanisms of Postbiotics}

\section{Prospective Role of Postbiotics in Modulating Intestinal Epithelial Barrier Integrity}

The intestinal epithelial cells act as a frontier in maintaining the synergistic balance between host molecules and microbiota. The intrusion of pathogens posits high risk of pathogenesis leading to various anomalies such as disruption of intestinal barrier, dysbiosis, and subsequently leaky gut. These factors induce panoply of highly coordinated defense mechanisms that restore barrier function, innate and adaptive immune response for restricting the entry of various pathogens. The intestinal barrier integrity gets disrupted with entry of SARS-CoV-2 that leads to various changes in the intestine that significantly impact the integrity of IEC. The different secretory metabolites of probiotics such as indole, bacteriocins, organic acids, secretory proteins, hydrogen peroxide, and nitric oxide (NO) have shown potential in reserving the intestinal barrier function by enhancing the expression of tight junctions, mucus secretion by goblet cells, and boosting the production of antimicrobial peptides [81-84]. The secretory proteins p40 and p75 have been reported to maintain the homeostasis of intestinal epithelial cells by two known mechanisms $[85,86]$. Firstly, these proteins lead to the transactivation of epidermal growth factor receptor (EGFR) followed by upregulation of proliferationinducing ligand (APRIL) expression in intestinal epithelial cells. The expression of APRIL induces the production of IgA as well as impaired the cytokine-induced apoptosis that helps in the clearance of the virus [87]. Secondly, these proteins also actuate the production of heat shock proteins Hsp72 and Hsp25 that has the ability to protect tight junction proteins as well as stimulate the phosphatidylinositol 3-kinase (PIK3)-dependent Akt pathway for the proliferation of gut epithelial cells. In addition to that, a soluble 


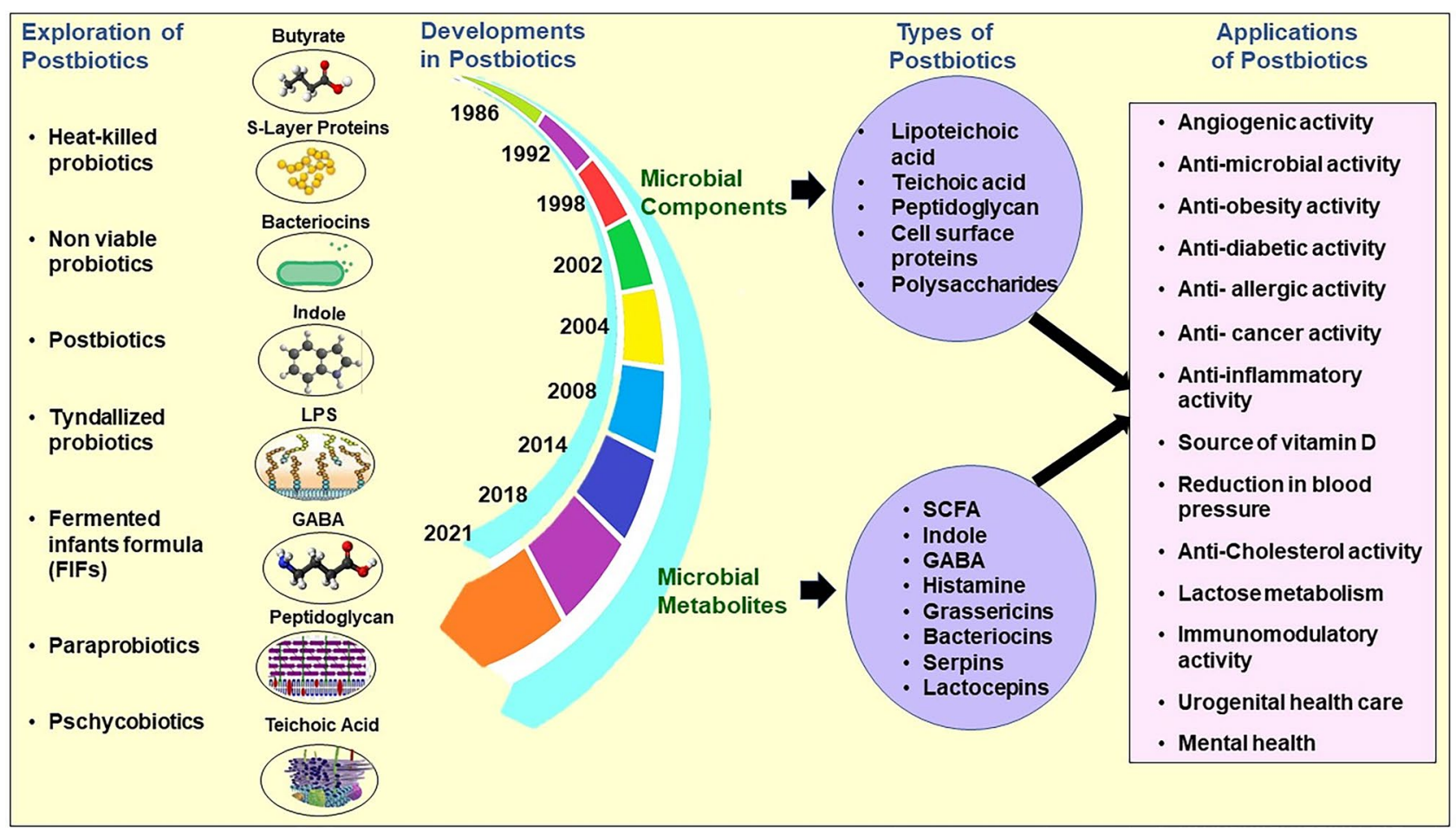

Fig. 1 Conception, timeline development, and applications of postbiotics

protein HM0539 from novel LGG enhances mucus secretion through mucin expression and protects intestinal integrity by the expression of tight junction proteins. Similarly, extracellular vesicles also known as outer membrane vesicles a lipid bilayer structure secreted by probiotics and other intestinal microbiota also impact the integrity of IECs. The extracellular vesicles released by Akkermansia muciniphila reduce the permeability of the intestine by upregulating the expression of claudin-3 protein through activation of AMPactivated protein kinase (AMPK) pathway [88]. The OMVs released by E. coli Nissle and E. coli ECOR63 have the ability to upregulate two tight junction proteins, i.e., ZO-1 and claudin-14 as well as expression of IL-22 that may prevent the entry of the virus into systemic circulation [89]. Furthermore, short-chain fatty acids (SCFAs) constituting acetate, propionate, and butyrate secreted by various probiotics by the fermentation of undigested dietary fibers (prebiotics) confer considerable role in intestinal integrity. Among SCFAs, butyrate is the most preferentially utilized energy source by IECs; thus, voluminous information has been available elucidating its effect on intestinal epithelial barrier. There are various mechanisms of SCFA by which it plays a crucial role that helps in maintaining the homeostasis of IECs. The binding of G-protein-coupled receptors, such as GPR109A, GPR43, and GPR41in IECs, strengthens the integrity of epithelial cells particularly the binding with GPR109A induces IL-18 that promotes intestinal homeostasis [90]. In addition to that, butyrate also induces the binding of AP-1 with MUC2 promoter followed by enhancement of expression of MUC2 mRNA level leading to enhanced production of mucin. As butyrate is also considered good histone, deacetylase inhibitor thus promotes acetylation of $\mathrm{H} 3$ and $\mathrm{H} 4$ histone proteins and methylation of $\mathrm{H} 3$ protein on the MUC2 promoter that boost the safety of mucosal barrier. The stability of hypoxia-inducible factor (HIF) by enhancing the expression of HIF target genes strengthening epithelial barriers is also linked with the action of butyrate [91]. The production of LL-37 (cathelicidin) confers antimicrobial property in IEC that maintains the functionality of IECs in the presence of pathogens [59]. The maintenance of TEER by binding of butyrate with various receptors mentioned above may confer protective role in IEC homeostasis. Apart from that, another secretory metabolite indole produced by $E$. coli Nissle maintains the TEER by downregulation of TNF- $\alpha$-mediated NF- $\mathrm{KB}$ signaling pathway facilitating the epithelial function [92]. The binding of indole 3-propionic acid (IPA) with one of the gut epithelial receptors, i.e., pregnane $\mathrm{X}$ receptor (PXR), facilitates the upregulation of tight junction proteins coding mRNAs followed by augmentation of production of claudins and occludins that is crucial for epithelial barrier integrity after viral infection. In addition to that, indole secreted by Bifid. infantis induces the activation of aryl hydrogen receptors (AhRs) that facilitates the upregulation of the protein expression of 


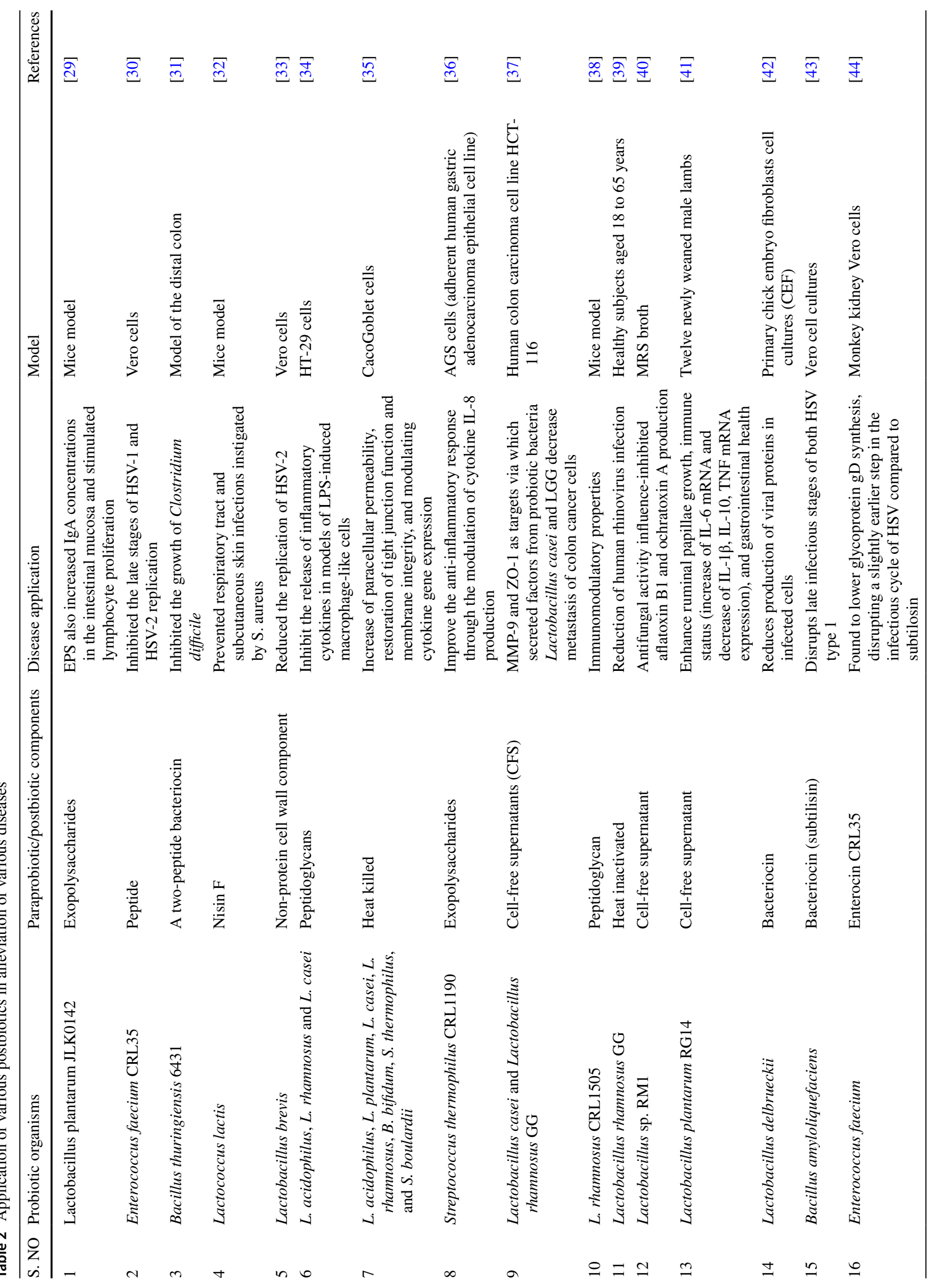




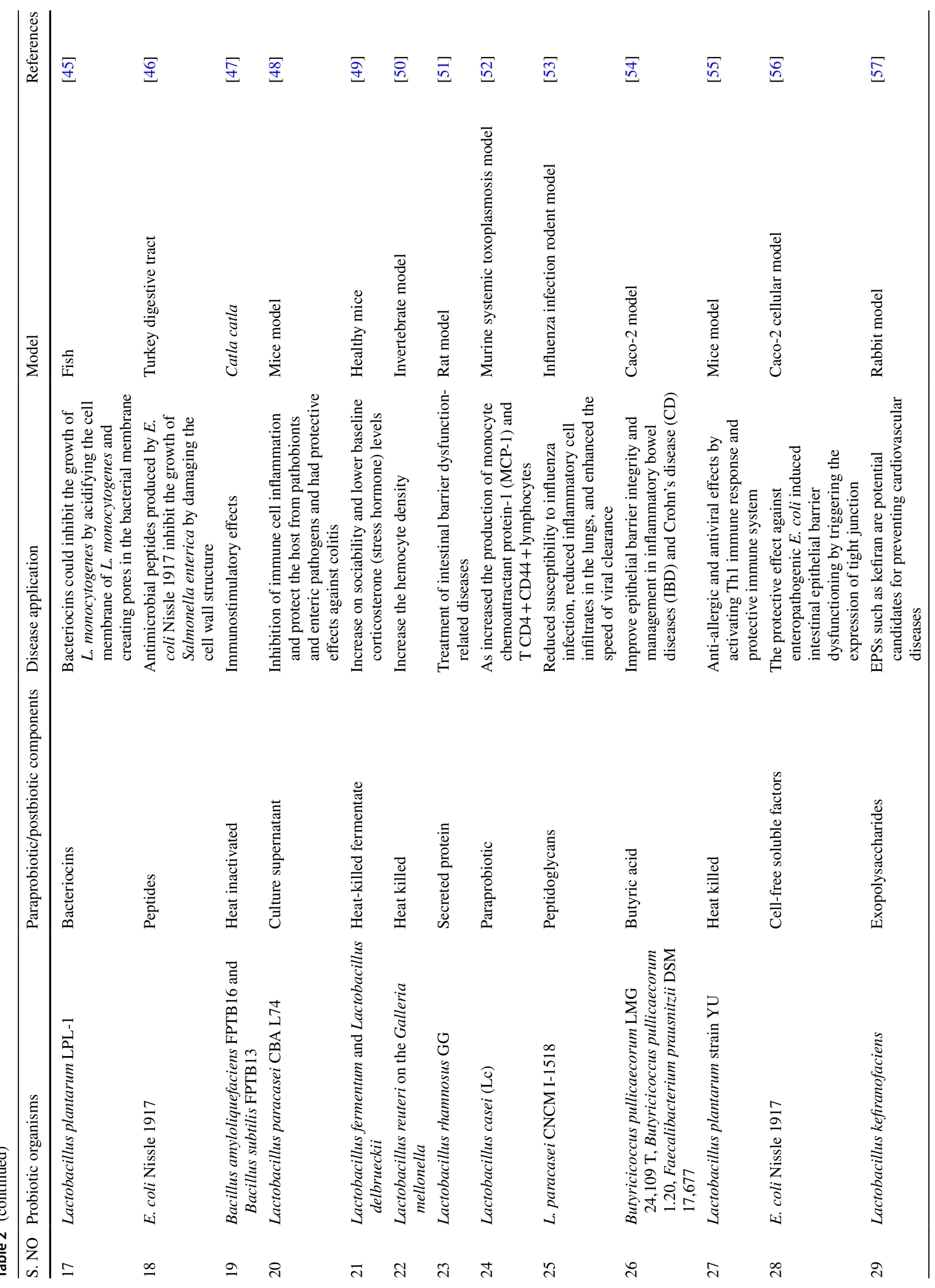




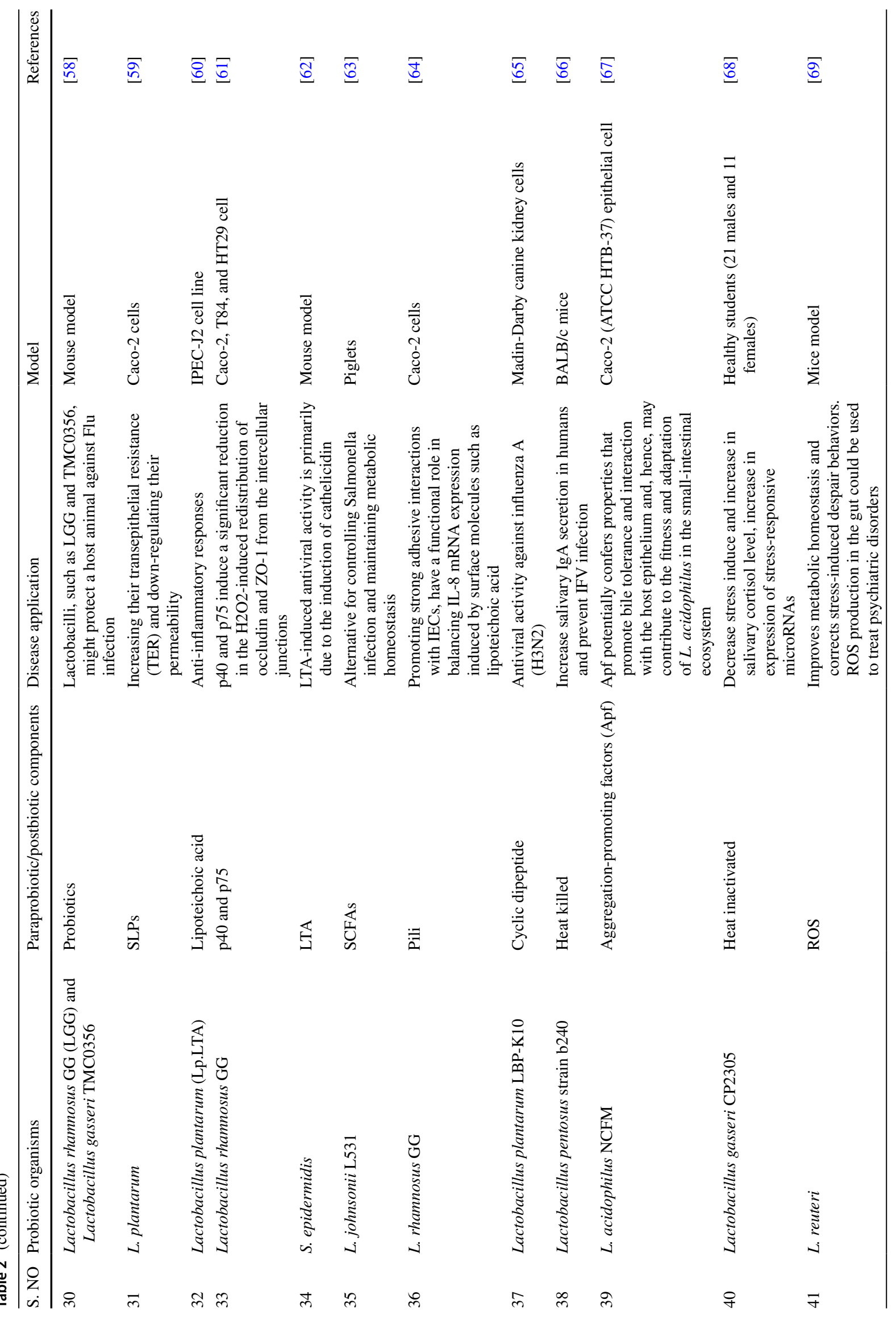




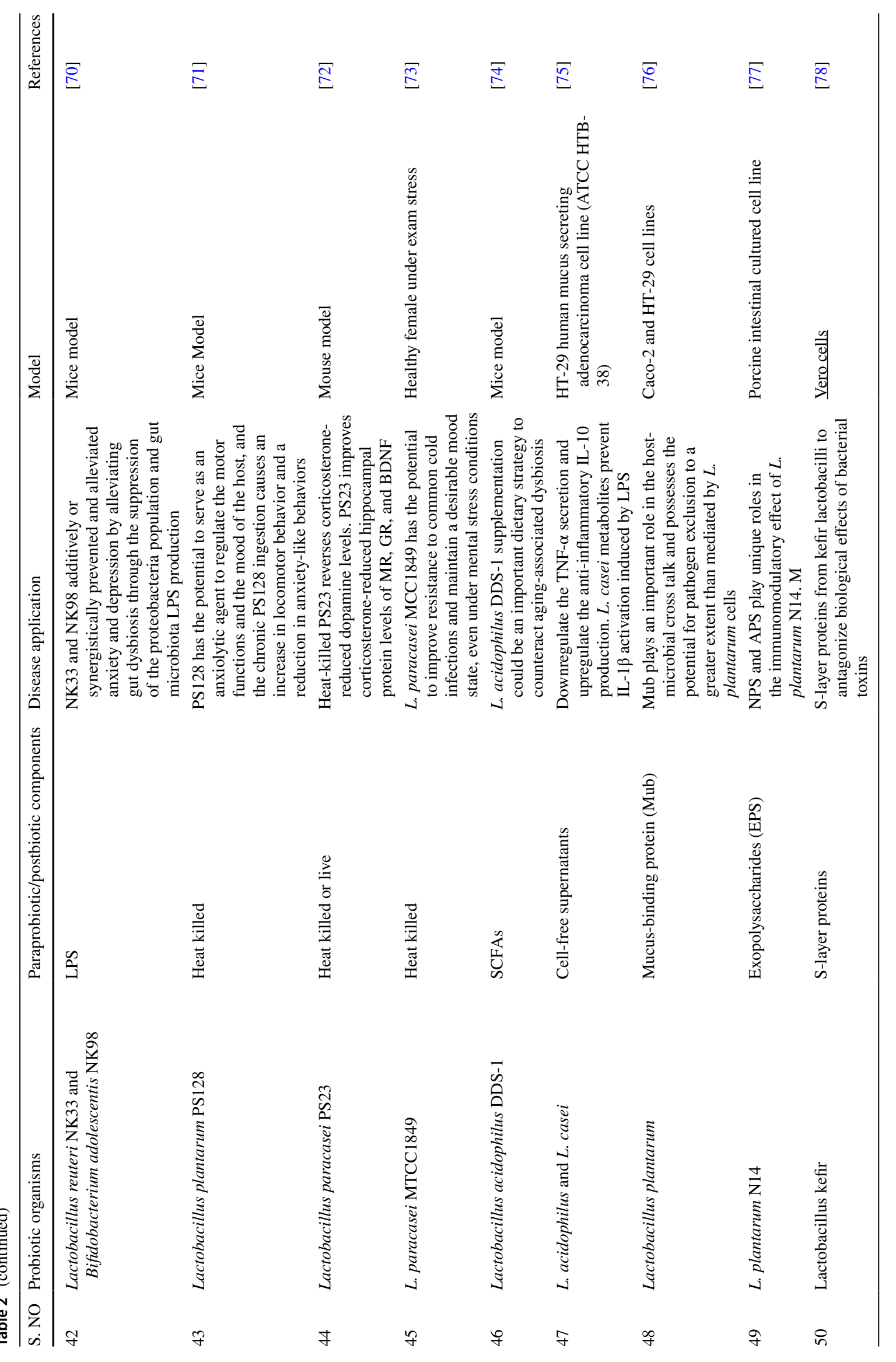


CYP1A1 followed by enhanced transcription of IL-22 [93]. This induction activates the secretion of antimicrobial peptides that may help in clearance of the virus. In addition to that, bacteriocins an important antimicrobial peptide is secreted by probiotics and other gut microbes. They are divided on the basis of mechanism of action, size, and inhibitory spectrum. The antiviral effect of various bacteriocins has been reported for the treatment for viral disorders by modulating the immune system. Research studies speculated that the replication of viruses at early and late stages has been inhibited by the application of enterocin AAR-74, enterocin AAR-71, erwiniocin NA4 secreted from Enterococcus faecium CRL35 and other species, and bacteriocin B1 from Lact. delbrueckii subsp bulgaricus. Apart from that, labyrinthopeptin A1 and A2 (LabyA1), carbacyclic lantibiotics, have also been shown to inhibit the virus entry into the host [94]. In addition to that, various other bacteriocins such as Nisin A and mutacin B-Ny266, microbisporicin, lacticin, thuricin $\mathrm{CD}$, and reuterin produced by various probiotic strains also reported to have antimicrobial activity that can be further warranted for reducing SARS-CoV-2 infection. Moreover, other surface components such as lipoteichoic acid, surface layer proteins (SLPs), capsular polysaccharide (CPS), pili, flagella, and lipopolysaccharides have been designated as microbial-associated molecular patterns (MAMPs) and credited with various bioactive properties. The infection of SARS-CoV-2 can be reduced by implementation of these molecules as they possess the binding affinity with various pattern recognition receptors (PRRs) such as toll-like receptors (TLRs) and NOD-like receptors (NLRs) that further regulate various signaling cascades including mitogen-activated protein kinases (MAPK), nuclear factor kappa B (NF-кB), peroxisome proliferator-activated receptor gamma, and other protease-depending signaling pathways in IECs. The alteration in TEER and integrity caused by viral entry into gut epithelium was maintained by surface layer proteins produced by Lactiplantibacillus plantarum and Lact. acidophilus. Micro integral membrane proteins (MIMPs), a small domain of SLPs from Lactiplantibacillus plantarum, have been shown to restore the integrity of IECs by enhancing the mRNA expression of various tight junction proteins claudin-1, occludin, and JAM-1 and F-actin [95, 96]. Furthermore, research studies depicted convincing evidence that the attachment of flagellin produced by $E$. coli Nissle $1917(E c N)$ with TLR5 receptor present in basolateral membrane of IEC activates phosphatidylinositol-3-kinase (PI3K)/AKT signaling pathway that reduce the expression of proinflammatory genes that further reduce inflammation [97]. It has also been reported that $\beta$-defensin, an antimicrobial peptide secreted by intestinal epithelial cells through NF- $\mathrm{KB}$ and activating protein-1 (AP-1) signaling pathways, has also been induced by EcN flagellin [98, 99]. Furthermore, pili, a filamentous accessory organ present in the surface of bacteria, have capability of maintaining the integrity of intestinal epithelial cells. Tight adhesion (Tad) pili of Bifid. breve UCC2003 have been reported to enhance the proliferation of IECs and mucus secretion [100]. Apart from that, $\mathrm{SpaC}$ pilin present in Lacticaseibacillus rhamnosus $\mathrm{GG}$ (LGG) activated the ERK phosphorylation pathway for the protection of intestinal epithelial barrier [101]. Moreover, F1C pili of EcN possess ability to bind with mannosylated glycoproteins in the intestine through TLR4-mediated pathway for strengthening the production of tight junction proteins. Furthermore, the reinforcement of intestinal microenvironment is done by capsular polysaccharides secreted by probiotics. CPS5 secreted by Bact. thetaiotaomicron reduced the antibiotic stress in IECs and improves the colonization of beneficial bacteria preventing the adhesion of pathogens $[102,103]$. In addition to that, the K5 capsular polysaccharide induces the expression of chemokines by activation of MAPK pathway by binding with TLR5 in IECs that reduce the inflammation in the gut [104]. The comprehensive mechanistic view of postbiotic action is represented in Fig. 2. Thus, by stating above facts, the postbiotics impart disparate effect on strengthening and maintaining the integrity of epithelial cells. The IECs have primary line of contact of SARs$\mathrm{CoV}-2$ entry and trigger severe immunological and biochemical changes in the gut; thus, by highlighting the effects of postbiotics, it is tangible to use these molecules for reducing the viral load and its clearance for combating COVID-19 in cutting-edge manner.

\section{Prospective Role of Postbiotics in Innate and Adaptive Immunity}

The invasion of SARS-CoV-2 into the host cell is immediately recognized by antigen-presenting cells (APCs) that leads to the stimulation of innate immune system. The various viral structural components such as glycoproteins, dsRNA, or other intermediate metabolic products of the virus collectively termed pathogen-associated molecular patterns (PAMPs) recognized by pattern recognition receptors (PRRs) conferred as primary viral sensors for mediating antiviral effector program by producing type I interferon (Type I IFN) response. However, 10\% of patients of COVID19 have been found to produce autoantibodies against type 1 IFN- $\gamma$ due to the mutations found in IFN genes that is associated with lymphopenia. Thus, various innate immunomodulatory molecules secreted by probiotics in the gut lumen may confer protecting role against deadly virus. Various postbiotic molecules stimulate the production of mucin from goblet cells, antimicrobial peptide as defensins, trefoil factor by paneth cells and secretory $\operatorname{IgA}$, heat shock proteins, and various p-glycoproteins that are responsible for maintaining innate immunity after the entry of the virus in the intestinal system. It is well proven that ACE-2 is a 


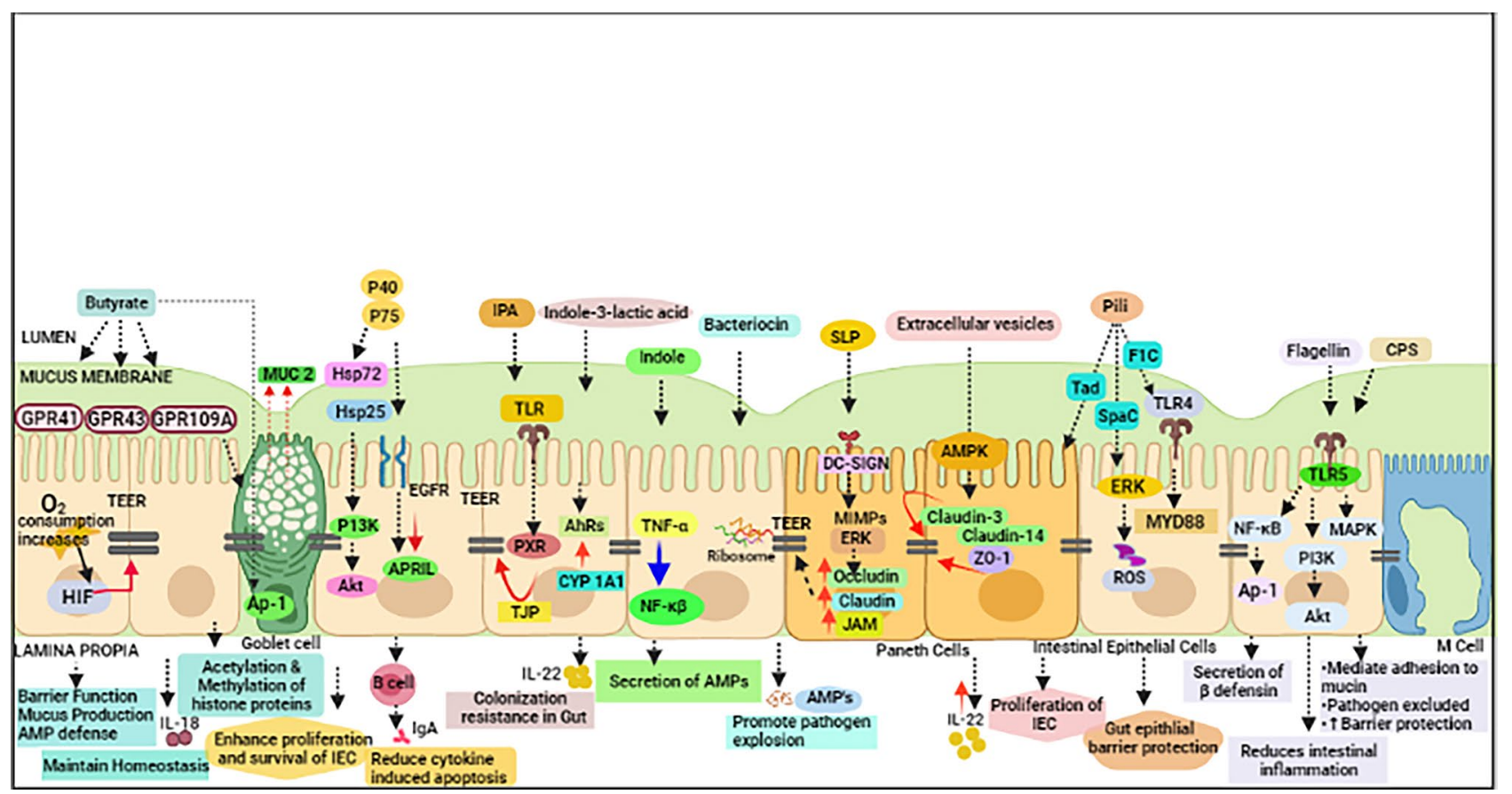

Fig. 2 Modulation of intestinal barrier integrity by various postbiotics (schematic illustration depicting the action of various postbiotic molecules affecting intestinal barrier functions) (red arrow representing the upregulation of various signaling pathways by various postbiotic molecules while blue arrow representing the downregulation of signaling pathways). AMPs, antimicrobial peptides; AP-1, activating protein; CSP, capsular polysaccharide; IECs, intestinal epithelial cells; HIF, hypoxia-inducible factor; GPCRs, G-protein-

viral receptor, and a type I cell surface glycoprotein is also found in enterocytes apart from type I and type II alveolar epithelial cells, the arterial smooth muscle tissues, arterial and venous endothelial cells, and renal and cardiovascular tissues. The basic function of ACE-2 is to perform amino acid homeostasis in the intestine that helps in the alleviation of intestinal inflammation, the expression of antimicrobial peptides, and maintenance of healthy gut microbiota. After the ACE2 receptor engagement, the processing of SARSCoV2 has been done by a type II transmembrane serine protease, TMPRSS2, present in intestinal epithelial cells and other serine proteases such as TMPRSS4 $[105,106]$ and ST14/matriptase are also expressed in mature enterocytes. The severity of infection is accelerated by the action of TMPRSS4. However, the expression of B0AT1 the sodiumdependent neutral amino acid transporter and amino acid (proline) SIT1 transporters on the luminal side of intestine epithelial cells is also associated with ACE2 expression. SARS-CoV-2 leads to the downregulation of ACE2 that further leads to the impairment in one of essential amino acid tryptophan, an essential modulator of kynurenine pathway for the formation of serotonin and other bioactive molecules by utilizing the indoleamine 2,3-dioxygenase (IDO) enzyme. coupled receptors; AhRs, aryl hydrogen receptors; P75 and P40, cell wall-associated hydrolase; EGFR, epidermal growth factor receptor; PI3K, phosphatidylinositol-3-kinase; PXR, pregnane X receptor; APRIL, a proliferation-inducing ligand; Hsp72 and Hsp25, heat shock proteins; ZO-1, zona occludin, 1; IPA, indole 3-propionic acid; TEER, transepithelial electrical resistance; TJPs, tight junction proteins; TLR, toll-like receptors

The various indole metabolites such as indole acetic acid, indole propionic acid, and tryptamine are generated during kynurenine pathway by metabolism of tryptophan that is secreted by probiotics that confers potential role in the differentiation of Treg cells and suppression of $\mathrm{T}$ effector cells [107]. Apart from these, indole metabolites also activate the production of IL-22 from natural killer T (NKT) cells, innate lymphoid cells (ILCs), and $\mathrm{CD}^{4+}$ lymphocytes cells by inducing the expression of IL-22 receptor on IECs by triggering Stat 3 pathway, mucin production, and release of AMPs by paneth cells $[108,109]$. The tryptophan impairment also leads to the aberrant expression of serum IL-6 and mammalian target of rapamycin (mTOR) protein kinase, p70S6kinase, that further impacts the production of various antimicrobial peptides such as lysozyme, cysteine-rich cationic peptides, RegIIIg, and $\alpha$-defensin HD5 and HD6 and alerted microbial diversity that enhances the susceptibility of intestine towards inflammation. Thus, the severe diarrhea in COVID-19 is the outcome of such alterations; therefore, supplementation of tryptophan in diet can be considered a preventive strategy for reducing the viral invasion in GIT. Furthermore, the secretion of antimicrobial peptides is also triggered by an effector molecule known as bacterial 
muramyl dipeptide (MDP) that is secreted by various $L a c$ tobacillus probiotics. The molecule is recognized by nucleotide-binding oligomerization domain2 (NOD-2) receptor that led to the activation of MAPK and NF-kB signaling pathway for secretion of various above-mentioned antimicrobial peptides [110,111]. Among all AMPs, the human defensin-5 (HD5) has highest affinity of $76.2 \mathrm{nM}$ with ACE2 receptor; thus, it can be acting as competitor with SARS$\mathrm{CoV}-2$ for binding. Moreover, the intestinal immune system also embraced the IgA, a non-inflammatory immunoglobulin acting as receptor for various pathogens. The secretion of $\operatorname{IgA}$ is mediated by intestinal B cells that can bind with polymeric Ig receptor (pIgR) which function as an antibody transporter expressed on the surface of intestinal epithelium facilitates the translocation of IgA dimmers in gut lumen and converted to secretory IgA. It was reported that lipoteichoic acids and peptidoglycan secreted by various probiotic species have the ability to induce the secretion of IgA with the help of TLR activation that has the ability to kill the virus particle. Research studies also speculated some aspects of antiviral defense through secretion of trefoil factors from mucin-producing cells have been upregulated by postbiotics. Furthermore, butyrate, an important type of SCFA, has been found to be low after viral infection that facilitates the upregulation of NRP-1 contributing towards the infectivity of SARS-CoV-2 through furin-mediated cleavage of viral spike proteins [112]. To abrogate the infectivity rate of the virus, butyrate as postbiotics can bind to the both GPR41 and GPR 43 receptors. The binding of butyrate with GPGR41 activates protein kinase A (PKA) pathway while binding with GPR43 activates phospholipase $\mathrm{C}$ for the production of diacyglycerol (DAG) that activates protein kinase $\mathrm{C}$ (PKC) and inositol triphosphate which trigger the release of intracellular $\mathrm{Ca}^{2+}$ ions that plays significant role in reduction of binding of viral spike protein with ACE2 receptor on IECs. The secretion of Vit D through probiotics or supplemented with diet triggers the attachment of vitamin $\mathrm{D}$ receptor (VDR) and p65 subunit of NF-kB pathway followed by its downregulation leads to the enhanced synthesis of tight junction proteins such as claudin and occludin that maintains the integrity of intestinal epithelium. Apart from that, the binding of VDR also downregulates the JAK/STAT pathway that leads to the enhanced synthesis of various antimicrobial peptides like LL-37 and $\beta$-defensin.

The signaling cascades described above foster phagocytosis of viral antigens by host macrophages that orchestrated the development of adaptive immune response [113]. In fact, the exaggerated immune response is manifested with enormous release of cytokines better termed as "cytokine storm" and secreted through various immune cells like innate macrophages, dendritic cells, natural killer cells, and the adaptive $\mathrm{T}$ and $\mathrm{B}$ lymphocytes. The colossal release of TNF- $\alpha$, IL-6, IL-1 $\beta$, IL-2, IFN $\alpha$, IFN $\beta$, and MCP-1 along with proinflammatory cytokines such as IL-1, IL-2, IL-7, G-CSF, IP-10, and MIP-1A is likely to contribute multiorgan failure and high mortality rate of people having COVID-19 at global scale [114]. However, research studies confirmed the application of heat-killed Lacticaseibacillus casei IBS041 (LC) and Lact. acidophilus AD031 (LA) that has been reported to decrease the expression of IL-6 and TNF- $\alpha$ and diminish the inflammation in IECs but the link with secreted components has not beet conclusively established yet. Similarly, the upregulation of IL-10 by inducing the expression of Treg cells has been reported for the reinforcement of intestinal homeostasis mediated through the secretory components of Bifid. breve. Furthermore, the internalization of probiotics either through $\mathrm{M}$ cells or paracellular transport through epithelial cells into payer's patch (PP) and subsequent release of their components may promote the secretion of $\operatorname{IgA}$ antibodies that is crucial for clearance of viral components [115]. The detailed mechanistic view of postbiotics is summarized in Fig. 3. Thus, these studies strongly support that various postbiotics play pivotal role in modulating the innate and adaptive immunity to reduce the burden of SARS-CoV-2 infection and proliferation in the gut. Thus, postbiotics could be a prospective armamentarium for abrogating the enigma of COVID-19 [116, 117].

\section{Prospective Role of Postbiotics in Mental Health}

The pandemic COVID-19 decimated more than three million deaths within a year despite the modern advancements in medical field. Apart from the death toll, more than 150 million recovered people have suffered from physical, emotional, and economic problems that leads to vicarious traumatization causing various mental health problems including depression, anxiety, and posttraumatic stress disorder (PTSD). Research studies defined the criteria for posttraumatic stress disorder (PTSD) varying from individuals who themselves suffered from COVID-19 and also witnessed the death of their family members, close relatives, and friends. The stress also encompasses the individuals greatly exposed to aversive information due to COVID-19. Recently, the people who have suffered from COVID-19 also faced the problem of aberrant cognition, memory loss, severe depression, and anxiety and thus considered emerging health concern at post-COVID scenario is better known as "Brain Fog"[117]. Though the current modality for diagnosing the maladies of the brain with MRI does not signify any damage or injury yet due to COVID-19 but as the gut plays pivotal role in COVID-19, there might be a chance that certain factors like gut dysbiosis [118] lead to alteration in neurotransmitters, adrenal gland secretion, and inflammation in nerve cells that aggravate the mental problems. The bifacial communication between the brain and gut forms the basis of "gut-brain axis" that affects the functionality of each other via immune, 


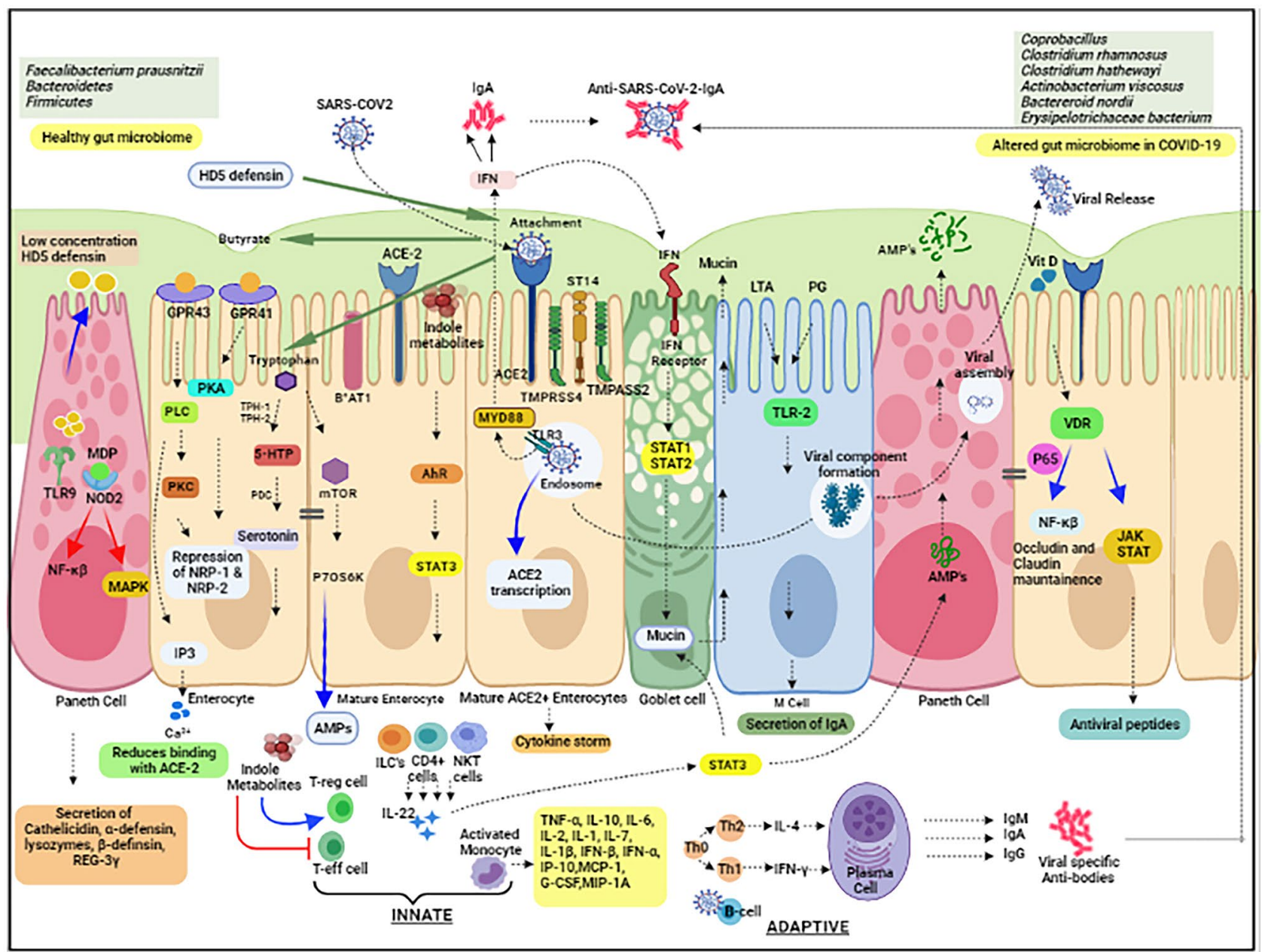

Fig. 3 Modulation of innate and adaptive immunity by various postbiotics (schematic illustration depicting the action of various postbiotic molecules affecting innate and adaptive immunity) (red arrow representing the upregulation of various signaling pathways by various postbiotic molecules while blue arrow representing the downregulation of signaling pathways; green arrow representing the reduction of postbiotic molecules after binding of SARS-CoV-2 with ACE-2 receptor) ACE2, angiotensin-converting enzyme; $\mathbf{B}_{\mathbf{0}} \mathbf{A T 1}$, amino acid transporter; NOD, nucleotide-binding oligomerization domain2
(NOD-2); IDO, indoleamine 2,3-dioxygenase; NKT, natural killer T; NRP-neuropilin; mTOR, mammalian target of rapamycin; PKA, protein kinase A; HD-5, human defensin-5; GPRs, G-protein receptors; IL, interleukin; IFN, interferon; JAK/STAT, Janus kinase/signal transducers and activators of transcription; MCP-1, monocyte chemoattractant protein,1; G-CSF, granulocyte colony-stimulating factor; IP-10, interferon gamma-induced protein 10; MIP-1A, macrophage inflammatory protein,1; VDR, vitamin D receptor

released by psychobiotics (as postbiotics) may provide more viable option for treating and managing COVID-19 in futuristic scenario. Research studies have proven that there exist three routes by which postbiotics may influence the PTSD in COVID-19. There is convincing evidence that various neurotransmitters such as acetylcholine, dopamine, gamma-aminobutyric acid (GABA), catecholamines, and serotonin have been secreted by probiotics that affect the normal functioning of the brain. We also know that the brain and gastrointestinal (GI) tract share a bifacial communication axis called "gut-brain axis" [119] that has the ability to affect other functions through neural, immune, endocrine, or humoral links [120]. Furthermore, homeostasis of mental medicaments. Therefore, various bioactive molecules 
hypothalamic-pituitary-adrenal axis (HPA) during stress conditions is also maintained by probiotic effector molecules and thirdly, the anti-inflammatory molecules released by probiotics have neuromodulatory effects. As COVID-19 is manifested by vicious cycle of altered gut microbiota profile, increased intestinal permeability and chronic inflammation lead to changes in mental framework through imbalances in neurotransmitter and hyperactive HPA axis which triggers stress, anxiety, depression, and impaired cognition gradually. The wide range of postbiotics secreted by probiotics may act via distinct pathways for overcoming the PTSD due to COVID-19 [121]. As it is evident, SARS-CoV-2 entry triggers the production of inflammatory cytokines ILs, tumor necrosis factor TNF- $\alpha$, and IFN- $\gamma$ that affects the permeability of intestinal cells leading to the movement of these cytokines by humoral pathways (through blood brain barrier), neural pathway (through vagus and spinal nerves), and cellular pathway (through monocytes or macrophages). These cytokines trigger the production of proinflammatory signals in the brain by binding with microglial receptors, disrupts the HPA homeostasis and impairment in regulation of neurotransmitters. This is a major mechanism that can be proposed for PTSD and brain fogging symptoms. The growing evidence of anti-depressive effect of GABA secreted by Lacticaseibacillus rhamnosus and Lacticaseibacillus casei enters through the neural route that modulates the GABAergic system and HPA axis in the brain. The alteration of mRNA expression of GABAA and GABAB receptors leads to reduction in depressive behavior. GABA secreted by Levilactobacillus brevis induces sound sleep and results in the aversion of depressive effects [122]. Furthermore, the cognitive impairments like loss of concentration and memory can be enhanced by secretion of serotonin and norepinephrine (NE) by Lact. hevleticus through the modulation of central 5-HT system, NE system, and HPA axis. In addition to that, histamines secreted by Limosilactobacillus reuteri in intestinal epithelial cells reduce the expression of proinflammatory cytokines that prevent the reduction of hippocampal brain-derived neurotrophic factor (BDNF), a biomarker for mental health [123]. Moreover, SCFAs such as butyrate play pivotal role in maintaining the gut barrier integrity that further impacts the expression of BDNF and modulation of 5-HT system in the central nervous system. The regulation of SCFAs in the brain leads to reduction in inflammation thus prevents anxiety and stress in the body. Furthermore, miscellaneous postbiotic molecules released by specific strains of probiotics also impart significant role in neuromodulation activities. The serpins secreted by Bifid. longum reach the brain through neural route that alter the inflammation by reduction of proinflammatory signals. In addition to that, gassericins secreted by Lact. gasseri promote the sleep and strengthen the composition of gut microbiome. Lactocepins secreted by Lacticaseibacillus paracasei facilitate the reduction of migration of inflammatory cytokines released during viral attack by maintaining the integrity of intestinal epithelium [124]. EPS secreted by Lact. kefiranofaciens confer immunomodulatory property that has potential to prevent the hyperactivity of HPA axis, and similar kind of polysaccharides produced through Bifid. infantis induces the production of NE neurotransmitter in CNS [125]. Furthermore, the conversion of albiflorin into BZA by Bifid. breve affects glutaminergic pathway via the humoral route. Furthermore, $\mathrm{H}_{2} \mathrm{O}_{2}$ released by Limosilactobacillus reuteri may prevent activation of IDO and circulation of KYN by proinflammatory cytokines that has the ability to reduce stress and depression in the host body [126]. The functionality of postbiotics on mental health is depicted in Fig. 4. Thus, based on the above discussion, it is conceivable to envision that postbiotics may have prospective role in abrogating various mental ailments during and post-COVID scenario. However, complete unravelling of pathophysiology must be required for completing the endeavor of postbiotic use in this aspect.

\section{Prospective Role of Postbiotics in the Management of Secondary Invasive Fungal Infections}

COVID-19 has been sweeping around the world and accentuated exhaustive research on finding various treatment modalities to overcome the high mortality rate has been visualized in the second wave. The associated co-morbidities such as immunocompromised conditions, diabetes, chronic obstructive pulmonary disease (COPD), and hematological malignancies as well as overwhelming utilization of corticosteroids and antibiotics, prolonged ventilation, and intensive care unit stay provide the lucrative opportunity for various secondary invasive opportunistic infections [127]. These infections have been characterized as oropharyngeal candidiasis (OPC), COVID-associated pulmonary aspergillosis (CAPA), bloodstream candida infections, mucor mycosis (black fungus and white fungus), and Mucor septicus (yellow fungus) [128-131]. The strategic diagnostic embodiments are critically needed for identifying the invasiveness of fungus that traverses the major parts of the body and require critical care management. The significant decrease in lymphocyte count and increment in neutrophil count together with aggressive inflammatory response lead to severe immunosuppression that is the major cause of developing these chronic infections. In fact, recent research emphasized the dysbiosis of mycobiota in COVID-19. The reduction in the population of Aspergillus and Penicillium and enhancement in the population of Candida glabrata were observed in COVID-19 patients. Furthermore, the gut mycobiota profile of COVID-19 patients highlighted the positive correlation of Mucoromycota with Fusicatenibacter and Aspergillus niger with diarrhea, while presence of Penicillium citrinum depicted negative 


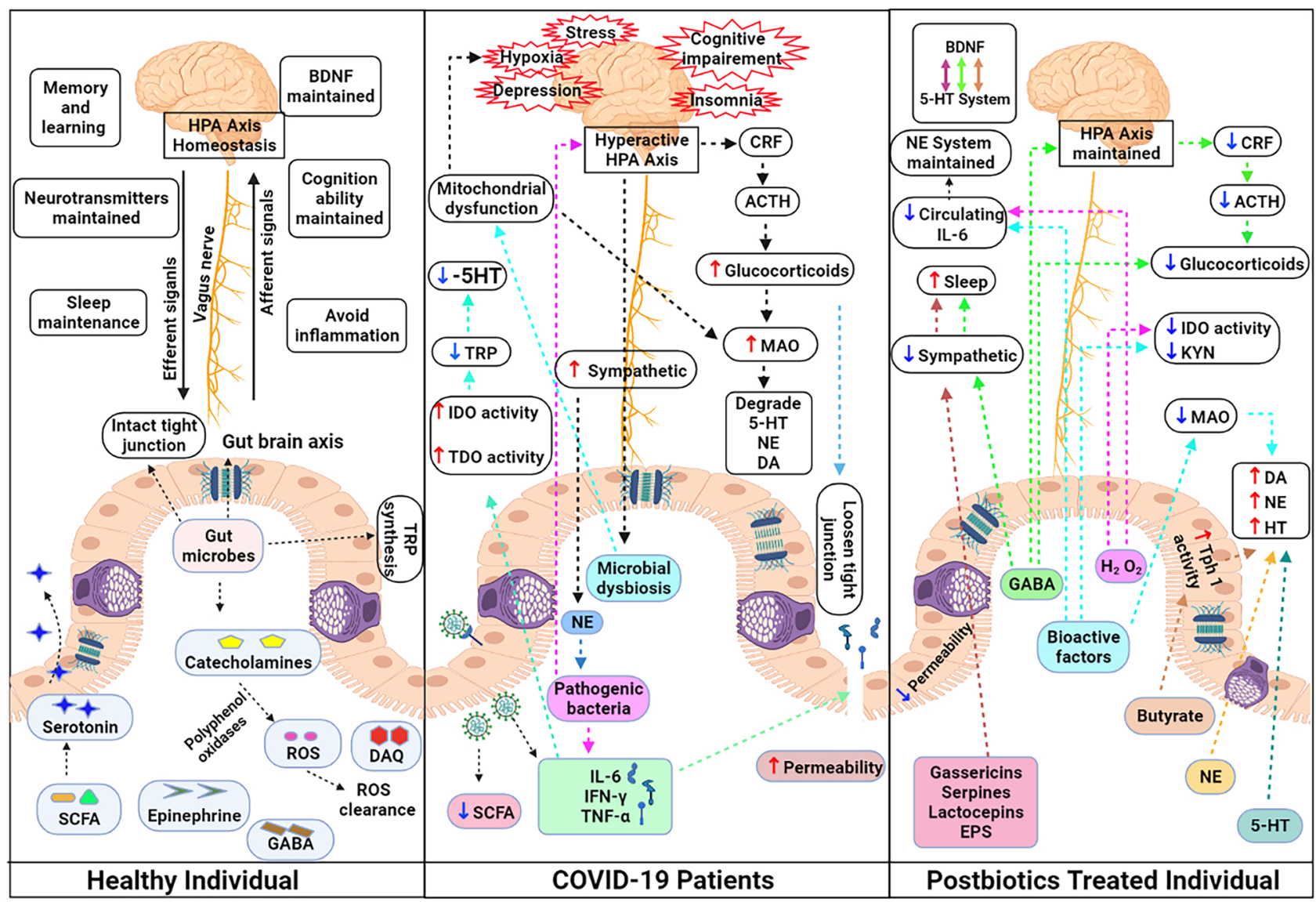

Fig. 4 Postbiotics in balancing hypothalamic-pituitary-adrenal axis and mental health during post-COVID regime (schematic illustration depicting the action of various postbiotic molecules affecting mental health) (red arrow representing the upregulation of various signaling pathways by various postbiotic molecules while blue arrow representing the downregulation of signaling pathways) BDNF, brain-derived neurotrophic factor; DA, dopamine; 5-HT, 5-hydroxytryptamine or serotonin; BZA, benzoic acids; dgk, diacylglycerol kinase; EPS, exopolysaccharide; GABA, gamma-Aminobutyric acid; GLP-1, glucagon-like peptide, 1; Glu, glutamate or glutaminergic; $\mathbf{H}_{\mathbf{2}} \mathbf{O}_{2}$, hydrogen peroxide; HPA, hypothalamic-pituitary-adrenal axis; IECs, intestinal epithelial cells; IDO, indoleamine 2,3-dioxygenase; IL-6, interleukin-6; KYN, kynurenine; NE, norepinephrine; ROS, reactive oxygen species; SCFA, short-chain fatty acid; Tph1, tryptophan hydroxylase 1; TRP, tryptophan

such as C. albicans, C. glabrata, C. tropicalis, C. krusei, C. kefyr, C. dubliniensis, and C. parapsilosis as well as A. flavus and $A$. parasiticus has been done by the supplementation of various probiotics majorly including Lactobacillus strains [133]. Recently, cell-free supernatant (CFS) as postbiotic, derived from Lacticaseibacillus paracasei 28.4 , has depicted potential inhibitory activity against $C$. auris [134]. In addition to that, capric acid as postbiotic component secreted by Saccromyces boulardii has potential to reduce the expression of various virulence genes such as inol, cshl, and hwpl in C. albicans [135]. Furthermore, it has been reported that the infection of various Mucor species, like mucor mycosis and mucor sepsis, leads to alteration in the integrity of intestinal epithelial cells and modulates the healthy gut microbiome. These findings suggest that different postbiotic molecules that have potential to modify the integrity of IECs (described in the "Prospective Role of Postbiotics in opment of biofilm. The inhibition of various Candida species 
Modulating Intestinal Epithelial Barrier Integrity" section) can be utilized for abrogating the deadly fungal infections. Though prodigious research is required to reach a convincing conclusion but rising data of resistant fungal strains and surge in immunocompromised patients due to prolonged antifungal treatments, the use of postbiotics is considered to be worthy ally for managing post-COVID-19 complications.

\section{Current Challenges and Future Perspectives}

The severe convulsion and wide-spread mortality have been seen across the globe due to the dreadful spread of COVID19 . The virus carries forward the legacy of mutation precisely by generating more infectious strains within a year. Currently, the exhaustive research has been pursued for the development of various diagnostic platforms, vaccines, and other pharmacological interventions for the effective control of this pandemic. Parallelly, mounting evidence of correlation of gut microbiome with severity of COVID-19 has also been highlighted. There is a growing enthusiasm for utilizing probiotics albeit their detailed mechanism of action is still under investigation due to inherent complexity and cross talk between host microbiome and invasive virus. Furthermore, their discordant proof of efficacy in some individuals leads to skepticism about their role as friends or foe. Thus, postbiotics may confer significant advantage over probiotics in reducing the severity of infection from deadly SARS-CoV-2. However, certain key questions need to be answered that is posing challenges for their massive utilization and acceptance both from therapeutic and regulatory perspective, such as: Which probiotic species are well suited for the retrieval of postbiotics? Which analytical method is best suited for their extraction? What is their effective delivery method inside the host, their stability, and shelf life? What are the relevant methodologies that could be used for assessing their biological and clinical effects? What are the bioprocessing strategies for the commercialization of postbiotics?

Till date, extensive studies have been pursued in animal models and in vitro platforms therefore translating in human body are quite challenging due to varied physiological conditions as well as the complex cross talk of host with their microbiome. The guidelines for recommending the use of postbiotics should also be rigorously formed for their safety and acceptance [136]. The pressing demand for comprehensive studies should be required for assessing the direct correlation between immunomodulatory activities of postbiotics and their suppressing effects by onset of predisposing disease features. Thus, well-designed multicentric clinical trials in humans using suitable postbiotic should be conducted for adopting these remarkable molecules at massive scale. However, diet, age, microbiome, and the surrounding environment confer significant impact on the outcome of postbiotics. Thus, there is a pressing need to shift from the conventional top-down approach of identifying efficient postbiotic molecules in healthy individuals and elucidating their mechanism of action for development of "precision postbiotics." The advent of affordable nextgeneration DNA and high-throughput sequencing and "multiomics" technologies (metagenomics, metatranscriptomics, metaproteomics) enhances our knowledge of structural and functional dynamism of gut microbiome that leads to the analysis of voluminous data that require advanced computational tools. The growing continuum of the development of computational intelligence methods like machine learning metamorphosizes the microbiological research and paves the way forward to digitalized microbiology [137]. The prolific application of machine learning has been visualized in last 5 years in microbiome studies that has focus on clarifying microbial taxonomy and their mutual interactions as well as also evaluating microbiome biomarkers of diagnosis of multiple diseases [138]. More recently, the efficacy of probiotic therapeutics has been evaluated by utilizing the ABIOME (A Bioreactor Imitation of the Microbiota Environment) utilizing machine learning algorithms at metabolome level [139]. The same approach can be well applied for microbiomebased diagnostic for COVID-19. The whole metagenomic fecal data, i.e., microbiome, mycobiome, and virome, gives longitudinal molecular and metabolite profiles of host and microbes interaction. Furthermore, 16sRNA sequencing data and other taxonomic markers can be used to study specific microbial diversity of an individual. The unique microbiome profile can be further modelled through various machine learning methods and utilizing the ABIOME, an artificial model of the human gastrointestinal tract that will give an idea of efficient probiotics and its effector molecules. This approach is better coined as bottom-up approach that can be assessed at both cellular (phenotypic perspective) and molecular level (genotypic perspective). An overview of proposed model for utilizing precision postbiotics is depicted in Fig. 5. The phenotypic perspective covers the screening of postbiotic effects by utilizing in vitro and ex vivo cell cultures as well as animal models comprising immune, neuronal, metabolic, or microbial read-outs. The genotypic perspective is based on selection of postbiotics through in silico prediction of their effects governing microbial or host pathways that impacts the severity of COVID-19. Based on microbiome profile, precision postbiotics will be given for the efficient management of this disease. However, the proposed scheme will foresee major challenge in collection of person-specific data with respect to their genetics, immune profiling, microbiome data, and anthropometrics as well as implementation of correct machine learning tools for optimum outcome. The road for the execution of the proposed framework seems to be overoptimistic and arduous in the current scenario but it is likely to be seen that in the next 


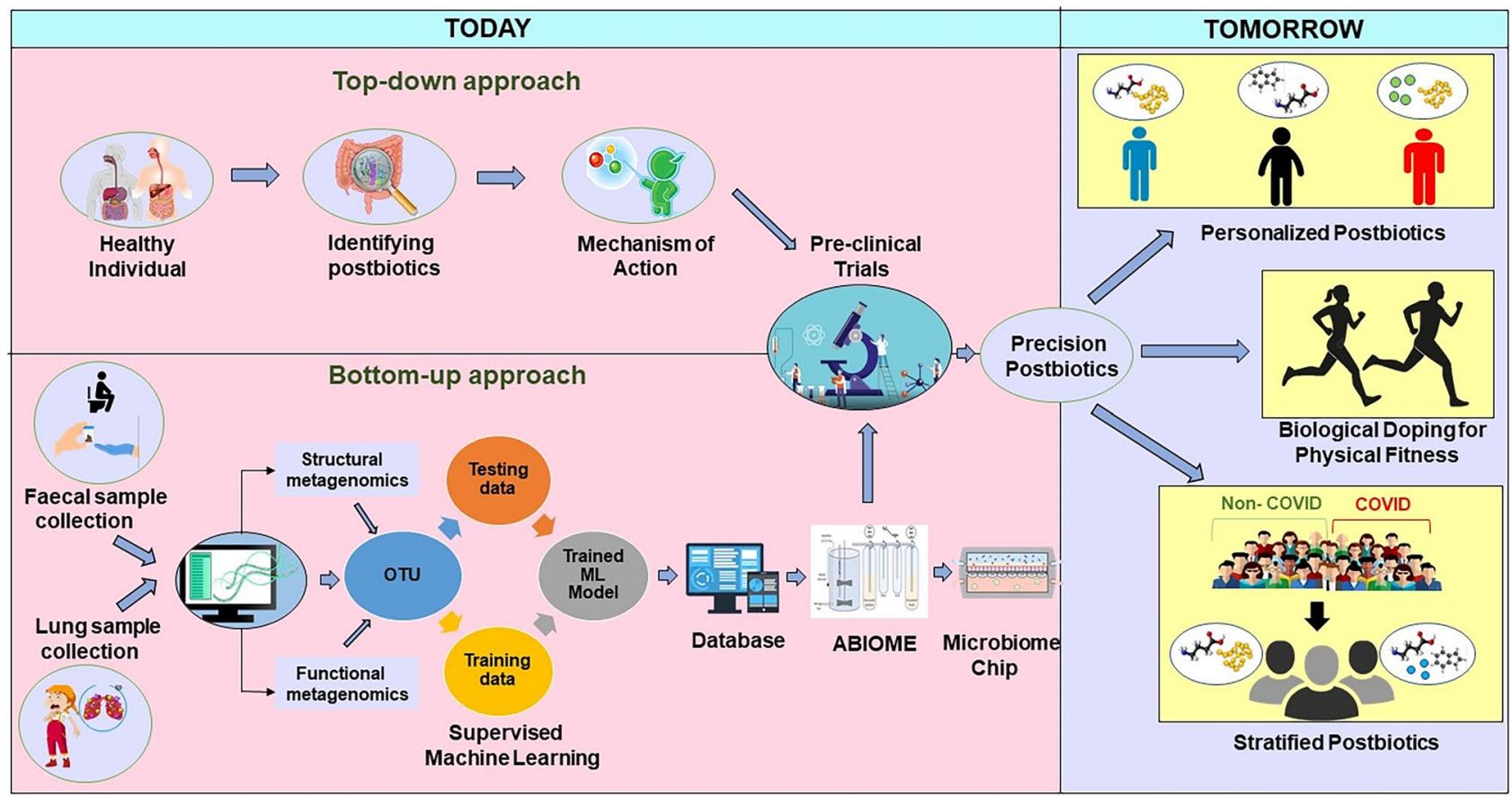

Fig. 5 Proposed model for the development of precision postbiotics to be used in the management of COVID-19 pandemic

few years every human has its own microbiome card that facilitates the use of postbiotics as personalized therapeutics depending on the prevalence of pathogen variants. Furthermore, recent studies reported the presence of bacterial genus Veillonella in the gut that metabolizes lactic acid to propionate and enables the enhancement of physical performance [140]. This concept leads in the emergence of biological doping where postbiotics can be used for modifying the physical fitness and performance. This signifies their role in enhancing or modulating the immunity of an individual that can also be explored in reducing the susceptibility or severity towards other viral infections.

\section{Conclusion}

The past decade has seen stupendous stride in underpinning the molecular mechanism and bioactive metabolites of probiotics. The continuous refurbishing of probiotic effector molecules as postbiotics and their health benefits has radically transformed the basic research to translational aspects. However, the scarcity of data on antiviral effect of postbiotics warrants comprehensive investigations, but the existing research evidences prove that these molecules possess magnificent properties from clinical, technological, and economic perspectives for controlling the virus. As today, the entire world is scourged by
COVID-19 pandemic, and working hard to overcome and control the current situation. Yet, its long-term effects need to be precisely investigated. The overwhelming utilization of repurposed drugs and antibiotics will be detrimental to our gut microbiome and it may lurk another menace behind COVID-19. Thus, it reminded us a very old adage of our ancestors that "It's all about gut feelings." By keeping this view in mind, the exploration of postbiotics as therapeutics is "carte blanche" provided us by our "buddy bugs." Looking forward for exploring the human internal bioreactor may be a ray of hope in dark clouds; thus, a vision of "precision postbiotics" will be certainly on horizon.

Acknowledgements The authors greatly acknowledge the support of Gautam Buddha University and Maharishi Dayanand University for writing this manuscript.

Author Contributions Barkha Singhal conceptualized the idea and wrote the manuscript and Krishna Kant Sharma has critically revised the manuscript by giving his meticulous suggestions. Muskan Pandey has formulated four figures and helps in technical assistance related to referencing of manuscript and Archana Bhati and Kumari Priya drawn the specialized diagrams depicting the mechanistic details of postbiotics in gastrointestinal region and made comprehensive tables of this manuscript. The authors also acknowledged the support of Biorender software for making Figs. 2, 3, and 4 in this manuscript.

Data Availability Not applicable.

Code Availability Not applicable. 


\section{Declarations}

Ethics Approval Not applicable.

Consent to Participate Not applicable.

Consent for Publication Yes.

Conflict of interest The authors declare no competing interests.

\section{References}

1. Wang X, Che Q, Ji X, Meng X, Zhang L, Jia R, Lyu H, Bai W, Tan L, Gao Y (2021) Correlation between lung infection severity and clinical laboratory indicators in patients with COVID-19: a cross-sectional study based on machine learning. BMC Infect Dis 21:1921-1929. https://doi.org/10.1186/s12879-021-05839-9

2. Gupta AV, Madhavan K, Sehgal N, Nair S, Mahajan TS, Sehrawat B, Bikdeli N, Ahluwalia JC, Ausiello EY, wan Freedberg DE et al (2020) Extrapulmonary manifestations of COVID-19. Nat Med 26:1017-1032. https://doi.org/10.1038/s/41591-020-0968-3

3. El-Elimat T, AlSamen MM, Almomani BA, AlSawalha NA, Alali FQ (2021) Acceptance and attitudes toward COVID-19 vaccines: a cross-sectional study from Jordan. PLoS One 16:e250555. https://doi.org/10.1371/journal.pone.0250555

4. Chattopadhyay I, Shankar EM (2021) SARS-CoV-2-indigenous microbiota nexus: does gut microbiota contribute to inflammation and disese severity in COVID-19? Front Cell Infect Microbiol 11:590874. https://doi.org/10.3389/fcmb.2021.590874

5. Aan FJ, Glibetic N, Montaya-Uribe V, Matter ML (2021) COVID19 and the microbiome: the gut-lung connection. Ref Mod Food Sci. https://doi.org/10.1016/B978-0-12-819265-8.00048-6

6. Yang Y, Huang W, Fan Y, Chen GQ (2021) Gastrointestinal microenvironment and the gut-lung axis in the immune responses of severe COVID-19. Front Mol Biosci 8:647508. https://doi.org/ 10.3389/fmolb.2021.647508

7. Gao QY, Chen YX, Fang JY (2020) Novel coronavirus infection and gastrointestinal tract. J Dig Dis 21:125-126. https://doi.org/ 10.1111/1751-2980.12851

8. Lamers MM, Beumer J, van der Vaart J, Knoops K, Puschhof J, Breugen TI, Ravelli RBG et al (2020) SARS-CoV-2 productively infects human gut enterocytes. Science 369:50-54. https://doi. org/10.1126/science.abc1669

9. Song Y, Liu P, Shi XL, Chu YL, Zhang J, Xia J, Gao XZ, Qu T, Wang MY (2020) SARS-CoV-2 induced diarrhoea as onset symptom in patient with COVID-19. Gut 69:1143-1144. https:// doi.org/10.1136/gutjnl-2020-320891

10. Segal JP, Mak JWY, Mullish BH, Alexander JL, Ng SC, Marchesi JR (2021) The gut microbiome: an under-recognized contributor to the COVID-19 pandemic? Therp Adv Gastroenterol 13. https://doi.org/10.1177/175628482097

11. Devaux CA, Lagier JC, Raoult D (2021) New insights into the physiopathology of COVID-19: SARS-CoV-2-associated gastrointestinal illness. Front Med 8:640073. https://doi.org/10.3389/ fmed.2021.640073

12. Baud D, Agri VD, Gibson GR, Reid G, Giannoni E (2020) Using probiotics to flatten the curve of coronavirus disease COVID2019 pandemic. Front Public Health 8:186. https://doi.org/10. 3389/fpubh.2020.00186

13. Lehtoranta L, Latvala S, Lehtinen MJ (2020) Role of probiotics in stimulating the immune system in viral respiratory tract infections. A narrative review Nutrients 12:3163. https://doi.org/10. 3390/nu12103163
14. Tomasik P, Tomasik P (2020) Probiotics, non-dairy prebiotics and postbiotics in nutrition. Appl Sci 10:1470. https://doi.org/ 10.3390/app10041470

15. Kurian SJ, Unnikrishnan MK, Miraj SS, Bagchi D, Banerjee M, Reddy BS, Rodrigues GS, Manu MK, Saravu K, Mukhopadhyay C, Rao M (2021) Probiotics in prevention and treatment of COVID-19: current perspective and future prospects. Arch Med Res 52:582-594. https:// doi.org/10.1016/j.arcmed.2021.03.02

16. Harper A, Vijayakumar V, Ouwehand AC, ter Haar J, Obis D, Espadaler J, Binda S, Desiraju S, Day R (2021) Viral infections, the microbiome and probiotics. Front Cell Infect Microbiol 10:596166. https://doi.org/10.3389/fcimb.2020.596166

17. Suez J, Zmora N, Segal E, Elinav E (2019) The pros, cons and many unknowns of probiotics. Nat Med 25:716-729. https://doi. org/10.1038/s41591-019-0439-x

18. Tsilingiri K, Rescigno M (2013) Postbiotics: what else? Benef Microbes 4:101-107. https://doi.org/10.3920/BM2012.0046

19. Zółkiewicz J, Marzec A, Ruszczy’nski M, Feleszko W (2020) Postbiotics-a step beyond pre and probiotics. Nutrients 12:2189. https://doi.org/10.3390/nu12082189

20. Su GL, Ko CW, Bercik P, Falck-Ytter Y, Sultan S, Weizman AV, Morgan RL (2020) AGA clinical practice guidelines on the role of probiotics in the management of gastrointestinal disorders. Gastroenterology 159:697-705. https://doi.org/10.1053/j.gastro. 2020.05.059

21. Homayouni Rad A, Aghebati Maleki L, Samadi Kafil H, Abbasi A (2020) Postbiotics: a novel strategy in food allergy treatment. Crit Rev Food Sci Nut 61:492-499. https://doi.org/10.1080/ 10408398.2020.1738333

22. Nataraj BH, Ali SA, Behare PV, Yadav H (2020) Postbioticsparabiotic: the new horizons in microbial biotherapy and functional foods. Microb Cell Fact 19:168. https://doi.org/10.1186/ s12934-020-01426-w

23. Shenderov BA (2013) Metabiotics: novel idea or natural development of probiotic conception. Micro Eco Health Dis 24. https:// doi.org/10.3402/mehd.v24i0.20399

24. Singh A, Vishwakarma V, Singhal B (2018) Metabiotics: the functional metabolic signatures of probiotics: current state-of-art and future research priorities. Adv Biosci Biotechnol 9:147-189. https://doi.org/10.4236/abb.2018.94012

25. de Almada CN, Almada CN, Martinez RCR, Sant'Ana AS (2016) Paraprobiotics: evidences on their ability to modify biological responses, inactivation methods and perspectives on their application in foods. Trends Food Sci Technol 58:96-114. https://doi. org/10.1016/j.tifs.2016.09.011

26. Salminen S, Collado MC, Endo A, Hill C, Lebeer S, Quigley EMM, Sanders ME, Shamir R, Swann JR, Szajewska H, Vinderola G (2021) The International Scientific Association of Probiotics and Prebiotics (ISAPP) consensus statement on the definition and scope of postbiotics. Nat Rev Gastroenterol Hepatol 18:649-667. https://doi.org/10.1038/s41575-021-00440-6

27. Shigwedha N, Sichel L, Jia L, Zhang L (2014) Probiotical cell fragments (PCFs) as "novel nutraceutical ingredients. J Biosci Med 2:43-55. https://doi.org/10.4236/jbm.2014.23007

28. Vandenplas Y, Zakharova I, Dmitrieva Y (2015) Oligosaccharides in infant formula: more evidence to validate the role of prebiotics. Br J Nutr 113:1339-1344. https://doi.org/10.1017/ S0007114515000823

29. Wang J, Wu T, Fang X, Min W, Yang W (2018) Characterization and immunomodulatory activity of an exopolysaccharide produced by Lactobacillus plantarum JLK0142 isolated from fermented dairy tofu. Int J Biol Macromol 115:985-993. https:// doi.org/10.1016/j.ijbiomac.2018.04.099

30. Wachsman MB, López EM, Ramirez JA, Galagovsky LR, Coto CE (2000) Antiviral effect of brassinosteroids against herpes 
virus and arenaviruses. Antivir Chem Chemother 11:71-77. https://doi.org/10.1177/095632020001100107

31. Rea MC, Sit CS, Clayton E, O'Connor PM, Whittal RM, Zheng J, Vederas JC, Ross RP, Hill C (2010) Thuricin CD, a posttranslationally modified bacteriocin with a narrow spectrum of activity against Clostridium difficile. Proc Natl Acad Sci USA 107:9352-9357. https://doi.org/10.1073/pnas.0913554107

32. Kwaadsteniet MDe, Doeschate KT, Dicks LM, (2009) Nisin $\mathrm{F}$ in the treatment of respiratory tract infections caused by Staphylococcus aureus. Lett Appl Microbiol 48:65-70. https:// doi.org/10.1111/j.1472-765X.2008.02488.X

33. Mastromarino P, Cacciotti F, Masci A, Mosca L (2011) Antiviral activity of Lactobacillus brevis towards herpes simplex virus type 2: role of cell wall associated components. Anaerobe 17:334336. https://doi.org/10.1016/j.anaerobe.2011.04.022

34. Wu Z, Pan D, Guo Y, Sun Y, Zeng X (2015) Peptidoglycan diversity and anti-inflammatory capacity in Lactobacillus strains. Carbohydr Polym 128:130-137. https://doi.org/10. 1016/j.carbpol.2015.04.026

35. Servi B, Ranzini F (2017) Protective efficacy of antidiarrheal agents in a permeability model of Escherichia coli-infected

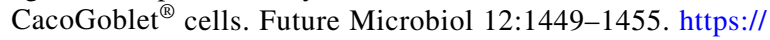
doi.org/10.2217/fmb-2016-0195

36. Marcial G, Villena J, Faller G, Hensel A, de Valdéz GF (2017) Exopolysaccharide-producing Streptococcus thermophilus CRL1190 reduces the inflammatory response caused by Helicobacter pylori. Benef Microbes 8:451-461. https://doi.org/ 10.3920/BM2016.0186

37. Escamilla J, Lane AM, Maitin V (2012) Cell free supernatants from probiotic Lactobacillus casei and Lactobacillus rhamnosus GG decrease colon cancer cell invasion invitro. Nutr Cancer 64:871-878. https://doi.org/10.1080/01635581.2012. 700758

38. Kolling Y, Salva S, Villena J, Alvarez S (2018) Are the immunomodulatory properties of Lactobacillus rhamnosus CRL1505 peptidoglycan common for all Lactobacilli during respiratory infection in malnourished mice? PLoS One 13:e0194034. https://doi.org/10.1371/journal.pone.0194034

39. Tapiovaara L, Kumpu M, Mäkivuokko H, Waris M, Korpela R, Pitkäranta A, Winther B (2016) Human rhinovirus in experimental infection after peroral Lactobacillus rhamnosus GG consumption, a pilot study. Int Forum Allergy Rhinol 6:848-853. https:// doi.org/10.1002/alr.21748

40. Shehata MG, Badr AN, El Sohaimy SA, Asker D, Awad TS (2019) Characterization of antifungal metabolites produced by novel Lactic acid bacterium and their potential application as food bio-preservatives. Ann Agri Sci 64:71-78. https://doi.org/ 10.1016/j.aoas.2019.05.002

41. Izuddin WI, Loh TC, Foo HL, Samsudin AA, Humam AM (2019) Postbiotic L. plantarum RG14 improves ruminal epithelium growth, immune status and upregulates the intestinal barrier function in post-weaning lambs. Sci Rep 9:9938. https://doi.org/ 10.1038/s41598-019-46076-0

42. Serkedjieva J, Danova S, Ivanova I (2000) Anti-influenza virus activity of a bacteriocin produced by Lactobacillus delbrueckii. Appl Biochem Biotechnol 88:85-298. https://doi.org/10.1385/ ABAB:88:1-3:285

43. Torres NI, Noll KS, Xu S, Li J, Huang Q, Sinko PJ, Wachsman MB, Chikindas ML (2013) Safety, formulation, and invitro antiviral activity of the antimicrobial peptide subtilisin against herpes simplex virus type 1. Probiotics Antimicrob Proteins 5:26-35. https://doi.org/10.1007/s12602-012-9123-X

44. Wachsman MB, Castilla V, de Ruiz Holgado AP, de Torres RA, Sesma F, Coto CE (2003) Enterocin CRL35 inhibits late stages of HSV-1 and HSV-2 replication in vitro. Antiviral Res 58:17-24. https://doi.org/10.1016/s0166-3542(02)00099-2
45. Wang Y, Qin Y, Zhang Y, Wu R, Li P (2019) Antibacterial mechanism of plantaricin LPL-1, a novel class IIa bacertiocin against Listeria monocytogenes. Food Control 97:87-93. https://doi.org/ 10.1016/j.foodcont.2018.10.025

46. Forkus B, Ritter S, Vlysidis M, Geldart K, Kaznessis YN (2017) Antimicrobial probiotics reduce Salmonella enterica in turkey gastrointestinal tracts. Sci Rep 7:40695. https://doi.org/10.1038/ srep40695

47. Kamilya D, Baruah A, Sangma T, Chowdhury S, Pal P (2015) Inactivated probiotic bacteria stimulate cellular immune responses of Catla catla (Hamilton) invitro. Probiotics Antimicrob Proteins 7:101-106. https://doi.org/10.1007/ s12602-015-9191-9

48. Zagato E, Mileti E, Massimiliano L, Fasano F, Budelli A, Penna G, Rescigno M (2014) Lactobacillus paracasei CBA L74 metabolic products and fermented milk for infant formula have antiinflammatory activity on dendritic cells invitro and protective effects against colitis and an enteric pathogen invivo. PLoS One 9:e87615. https://doi.org/10.1371/journal.pone.0087615

49. Warda AK, Rea K, Fitzgerald P, Hueston C, Gonzalez-Tortuero E, Dinan TG, Hill C (2019) Heat-killed Lactobacilli alter both microbiota composition and behavior. Behav Brain Res 362:213223. https://doi.org/10.1016/j.bbr.2018.12.047

50. Geraldo B, Batalha MN, Milhan N, Rossoni RD, Scorzoni L, Anbinder AL (2020) Heat-killed Lact. reuteri and cell-free culture supernatant have similar effects to viable probiotics during interaction with Porphyromonas gingivalis. J Periodontal Res 55:215-220. https://doi.org/10.1111/jre.12704

51. Gao J, Li Y, Wan Y, Hu T, Liu L, Yang S, Gong Z, Zeng Q, Wei Y, Yang W, Zeng Z, He X, Huang SH, Cao H (2019) A novel postbiotic from Lactobacillus rhamnosus GG with a beneficial effect on intestinal barrier function. Front Microbiol 10:477. https://doi.org/10.3389/fmicb.2019.00477

52. Salas-Lais AG, Robles-Contreras A, Balderas-Lopez JA, Bautista-de Lucio VM (2020) Immunobiotic and paraprobiotic potential of Lactobacillus casei in a systemic toxoplasmosis murine model. Microorganisms 8:113. https://doi.org/10.3390/microorganisms8010113

53. Belkacem N, Serafini N, Wheeler R, Derrien M, Boucinha L, Couesnon A, Cerf-Bensussan N et al (2017) Lactobacillus paracasei feeding improves immune control of influenza infection in mice. PLoS One 12:e0184976. https://doi.org/10.1371/journal. pone. 018497611450

54. Geirnaert A, Calatayud M, Grootaert C, Laukens D, Devriese S, Smagghe G, De Vos M, Boon N, Van de Wiele T (2017) Butyrate-producing bacteria supplemented invitro to Crohn's disease patient microbiota increased butyrate production and enhanced intestinal epithelial barrier integrity. Sci Rep 7:11450. https://doi.org/10.1038/s41598-017-11734-8

55. Kawashima T, Hayashi K, Kosaka A, Kawashima M, Igarashi T, Tsutsui H, Tsuji NM, Nishimura I, Hayashi T, Obata A (2011) Lactobacillus plantarum strain YU from fermented foods activates Th1 and protective immune responses. Int Immunopharmacol 11:2017-2024. https://doi.org/10.1016/j.intimp.2011.08.013

56. Kolling Y, Salva S, Villena J, Alvarez S (2018) Are the immunomodulatory properties of Lact. rhamnosus CRL1505 peptidoglycan common for all Lactobacilli during respiratory infection in malnourished mice? PLoS One 13:e0194034. https://doi. org/10.1371/journal.pone.0194034

57. Maeda H, Zhu X, Omura K, Suzuki S, Kitamura S (2004) Effects of an exopolysaccharide (kefiran) on lipids, blood pressure, blood glucose and constipation. BioFactors 22:197-200. https://doi.org/ 10.1002/biof.5520220141

58. Kawase M, He F, Kubota A, Harata G, Hiramatsu M (2010) Oral administration of Lactobacilli from human intestinal tract protects mice against influenza virus infection. Lett Appl Microbiol 51:6-10. https://doi.org/10.1111/j.1472-765X.2010.02849.x 
59. Yang B, Good D, Mosaiab T, Liu W et al (2020) Significance of LL-37 on immunomodulation and disease outcome. Biomed Res Int 2020:8349712. https://doi.org/10.1155/2020/8349712

60. Kim KW, Kang SS, Woo SJ, Park OJ, Ahn KB, Song KD, Lee HK, Yun CH, Han SH (2017) Lipoteichoic acid of probiotic Lactobacillus plantarum attenuates poly I:C-induced IL-8 production in porcine intestinal epithelial cells. Front Microbiol 8:1827. https://doi.org/10.3389/fmicb.2017.01827

61. Seth A, Yan F, Polk DB, Rao RK (2008) Probiotics ameliorate the hydrogen peroxide-induced epithelial barrier disruption by a PKC- and MAP kinase-dependent mechanism. Am J Physiol Gastrointest Liver Physiol 294:1060-1069. https://doi.org/10. 1152/ajpgi.00202.2007

62. Wang Z, MacLeod DT, Di Nardo A (2012) Commensal bacteria lipoteichoic acid increases skin mast cell antimicrobial activity against vaccinia viruses. J Immunnol 189:1551-1558. https://doi. org/10.4049/jimmunol.1200471

63. He T, Zhu YH, Yu J, Xia B, Liu X, Yang GY, Su JH, Guo L, Wang ML, Wang JF (2019) Lactobacillus johnsonii L531 reduces pathogen load and helps to maintain short-chain fatty acid levels in the intestine of pigs challenged with Salmonella entericainfantis. Vet Microbiol 230:187-194. https://doi.org/10. 1016/j/vetmic.2019.02

64. Lebeer S, Claes I, Tytgat HL, Verhoeven TL, Marien E, von Ossowski I, Reunanen J, Palva A, Vos WN, Keersmaecker SC, Vanderleyden J (2012) Functional analysis of Lactobacillus rhamnosus GG pili in relation to adhesion and immunomodulatory interactions with intestinal epithelial cells. Appl Environ Microbiol 78:185-193. https://doi.org/10.1128/AEM.06192-11

65. Kwak MK, Liu R, Kwon JO, Kim MK, Kim AH, Kang SO (2013) Cyclic dipeptides from Lactic acid bacteria inhibit proliferation of the influenza A virus. J Microbiol 51:836-843. https://doi.org/ 10.1007/s12275-013-3521-y

66. Kobayashi N, Saito T, Uematsu T, Kishi K, Toba M, Kohda N, Suzuki T (2011) Oral administration of heat-killed Lactobacillus pentosus strain b240 augments protection against influenza virus infection in mice. Int Immunopharmacol 11:199-203. https://doi. org/10.1016/j.intimp.2010.11.019

67. Goh YJ, Klaenhammer TR (2010) Functional roles of aggregationpromoting-like factor in stress tolerance and adherence of Lactobacillus acidophilus NCFM. Appl Environ Microbiol 76:5005-5012. https://doi.org/10.1128/AEM.00030-10

68. Nishida K, Sawada D, Kuwano Y, Tanaka H, Sugawara T, Aoki Y, Rokutan K (2017) Daily administration of paraprobiotic Lactobacillus gasseri CP2305 ameliorates chronic stress-associated symptoms in Japanese medical students. J Funct Foods 36:112 121. https://doi.org/10.1016/j.jff.2017.06.031

69. Marin IA, Goertz JE, Ren T et al (2017) Microbiota alteration is associated with the development of stress-induced despair behavior. Sci Rep 7:43859. https://doi.org/10.1038/srep43859

70. Jang HM, Lee KE, Kim DH (2019) The preventive and curative effects of Lactobacillus reuteri NK33 and Bifidobacterium adolescentis NK98 on immobilization stress-induced anxiety/ depression and colitis in mice. Nutrients 11:819. https://doi.org/ 10.3390/nu11040819

71. Liu WH, Chuang HL, Huang YT, Wu CC, Chou GT, Wang S, Tsai YC (2016) Alteration of behavior and monoamine levels attributable to Lactobacillus plantarum PS128 in germ-free mice. Behav Brain Res 298:202-209. https://doi.org/10.1016/j. bbr.2015.10.046

72. Wei CL, Wang S, Yen JT, Cheng YF, Liao CL, Hsu CC, Wu CC, Tsai YC (2019) Antidepressant-like activities of live and heatkilled Lactobacillus paracasei PS23 in chronic corticosteronetreated mice and possible mechanisms. Brain Res 1711:202-213. https://doi.org/10.1016/j.brainres.2019.01.025
73. Murata M, Kondo J, Iwabuchi N, Takahashi S, Yamauchi K, Abe F, Miura K (2018) Effects of paraprobiotic Lactobacillus paracasei MCC1849 supplementation on symptoms of the common cold and mood states in healthy adults. Benef Microbes 9:855-864. https://doi.org/10.3920/BM2017.0197

74. Vemuri R, Gundamaraju R, Shinde T, Perera AP, Basheer W, Southam B, Gondalia SV et al (2019) Lactobacillus acidophilus DDS-1 modulates intestinal-specific microbiota, short-chain fatty acid and immunological profiles in aging mice. Nutrients 11:1297. https://doi.org/10.3390/nu11061297

75. DeMarco S, Sichetti M, Muradyan D, Piccioni M, Traina G, Pagiotti R, Pietrella D (2018) Probiotc cell free supernatant exhibited antiinflammatory and anti-oxidant activity on human gut epithelial cells and macrophages stimulated with LPS. Evi Based Complement Alternat Med 2018:1756308. https://doi.org/10.1155/208/1756308

76. Singh KS, Kumar S, Mohanty AK, Grover S, Kaushik JK (2018) Mechanistic insights into the host-microbe interaction and pathogen exclusion mediated by the Mucus-binding protein of Lactobacillus plantarum. Sci Rep 8:14198. https://doi.org/10.1038/ s41598-018-32417-y

77. Murofushi Y, Villena J, Morie K, Kanmani P, Tohno M et al (2015) The Toll-like receptor family protein RP105/MD1 complex is involved in the immunoregulatory effect of exopolysaccharides from Lactobacillus plantarum N14. Mol Immunol 64:63-75. https://doi.org/10.1016/j.molimm.2014.10.027

78. Carasi P, Trejo FM, Pérez PF, De Antoni GL, Serradell M (2012) Surface proteins from Lactobacillus kefir antagonize invitro cytotoxic effect of Clostridium difficile toxins. Anaerobe 18:135-142. https://doi.org/10.1016/j.anaerobe.2011.11.002

79. Anwara F, Altayba HN, Al-Abbasia FA, Al-Malkia AL, Kamal MA, Kumar V (2020) Antiviral effects of probiotic metabolites on COVID-19. J Biomol Struct Dyn 2020:4175-4184. https:// doi.org/10.1080/07391102.2020.1775123

80. Gauteir T, Gall SD, Sweidan A, Tamanai-Shacoori Z, JolivetGougeon A, Loreal O, Bousarghin L (2021) Next-generation probiotics and their metabolites in COVID-19. Microogansims 9:941. https://doi.org/10.3390/microorgansims9050941

81. Lui Q, Yu Z, Tian FF, Zhao J, Zhang H, Zhai Q, Chen W (2020) Surface components and metabolites of probiotics for regulation of intestinal epithelial barrier. Microb Cell Fact 19:23. https:// doi.org/10.1186/s12934-020-1289-4

82. Dicks LMT, Dreyer L, Smith C, van Staden AD (2018) The fate of bacteriocins in the human gastro-intestinal tract: do they cross the gut-blood barrier? Front Microbiol 9:2297. https://doi.org/10. 3389/fmicb.2018.02297

83. Bansal T, Alaniz RC, Wood TK, Jayaraman A (2010) The bacterial signal indole increases epithelial-cell tight-junction resistance and attenuates indicators of inflammation. Proc Natl Acad Sci USA 107:228-233. https://doi.org/10.1073/pnas.0906112107

84. Olson N, Greul AK, Hristova M, Bove PF, Kasahara DI, an der Vielt A, (2009) Nitric oxide and airway epithelial barrier function: regulation of tight junction proteins and epithelial permeability. Arch Biochem Biophys 484:205-213. https://doi.org/10. 1016/j.abb.2008.11.027

85. Shen X, Liu L, Peek RM, Acra SA, Moore DJ, Wilson KT, He F, Polk DB, Yan F (2018) Supplementation of p40, a Lactobacillus rhamnosus GG-derived protein, in early life promotes epidermal growth factor receptor dependent intestinal development and long-term health outcomes. Mucosal Immunol 11:1316-1328. https://doi.org/10.1038/s41385-018-0034-3

86. Deng Y, McDonald OG, Means AL Jr, Peek RM et al (2021) Exposure to p40 in early life prevents intestinal inflammation in adulthood through inducing a long-lasting epigenetic imprint on TGF $\beta$. Cell Mol Gastroenterol Hepatol 11:1327-1345. https:// doi.org/10.1016/j.jcmgh.2021.01.004 
87. Wang Y, Liu L, Moore DJ, Shen X, Peek RM, Acra SA et al (2017) An LGG-derived protein promotes IgA production through upregulation of APRIL expression in intestinal epithelial cells. Mucosal Immunol 10:373-384. https://doi.org/10.1038/mi. 2016.57

88. Chelakkot C, Choi Y, Kim DK, Park HT, Ghim J, Kwon Y, Jeon J, Kim MS, Jee YK, Gho YS, Park HS, Kim YK, Ryu SH (2018) Akkermansia muciniphila-derived extracellular vesicles influence gut permeability through the regulation of tight junctions. Exp Mol Med 50:e450. https://doi.org/10.1038/emm.2017.282

89. Cañas MA, Fábrega MJ, Giménez R, Badia J, Baldomà L (2018) Outer membrane vesicles from probiotic and commensal Escherichia coli activate NOD1-mediated immune responses in intestinal epithelial cells. Front Microbiol 9:498. https://doi.org/10. 3389/fmicb.2018.00498

90. Bilotta AJ, Cong Y (2019) Gut microbiota metabolite regulation of host defenses at mucosal surfaces: implication in precision medicine. Precis Clin Med 2:110-119. https://doi.org/10.1093/ pcmedi/pbz008

91. Burger-van Paassen N, Vincent A, Puiman PJ, van der Sluis M, Bouma J, Boehm G, van Goudoever JB, van Seuningen I, Renes IB (2009) The regulation of intestinal mucin MUC2 expression by short-chain fatty acids: implications for epithelial protection. Biochem J 420:211-219. https://doi.org/10.1042/BJ20082222

92. Damoogh S, Vosough M, Hadifar S et al (2021) Evaluation of $E$. coli nissle 1917 derived metabolites in modulating key mediator genes of the TLR signaling pathway. BMC Res Notes 14:156. https://doi.org/10.1186/s13104-021-05568-x

93. Hattori SI, Higashi-Kuwata N, Hayashi H, Allu SR, Raghavaiah $\mathrm{J}$ et al (2021) A small molecule compound with an indole moiety inhibits the main protease of SARS-CoV-2 and blocks virus replication. Nat Commun 12:668. https://doi.org/10.1038/ s41467-021-20900-6

94. Prochnow H, Rox K, Birudukota NVS et al (2020) Labyrinthopeptins exert broad-spectrum antiviral activity through lipidbinding-mediated virolysis. J Virol 94:e01471-e1519. https:// doi.org/10.1128/JVI.01471-19e01471-19

95. Zhihua L, Zhang P, Ma Y, Chen H, Zhou Y, Zhang M, Chu Z, Qin H (2011) Lactobacillus plantarum prevents the development of colitis in IL-10-deficient mouse by reducing the intestinal permeability. Mol Biol Rep 38:1353-1361. https://doi.org/10.1007/ s11033-010-0237-5

96. Liu Z, Shen T, Zhang P, Ma Y, Qin H (2011) Lactobacillus plantarum surface layer adhesive protein protects intestinal epithelial cells against tight junction injury induced by enteropathogenic Escherichia coli. Mol Biol Rep 38:3471-3480. https://doi.org/ 10.1007/s11033-010-0457-8

97. Song WS, Jeon YJ, Namgung B, Hong M, Yoon SI (2017) A conserved TLR5 binding and activation hot spot on flagellin. Sci Rep 7:40878. https://doi.org/10.1038/srep40878

98. Wehkamp J, Harder J, Wehkamp K et al (2004) NF-kappaB- and AP-1-mediated induction of human beta defensin-2 in intestinal epithelial cells by Escherichia coli Nissle 1917: a novel effect of a probiotic bacterium. Infect Immun 72:5750-5758. https://doi. org/10.1128/IAI.72.10.5750-5758.2004

99. Lewis SB, Prior A, Ellis SJ, Cook V, Chan SS, Gelson W, Schüller S (2016) Flagellin induces $\beta$-defensin 2 in human colonic exvivo infection with enterohemorrhagic Escherichia coli. Front Cell Infect Microbiol 6:68. https://doi.org/10.3389/fcimb.2016.00068

100. O'Connell MM, Zomer A, Leahy SC, Reunanen J, Bottacini F, Claesson MJ, O’Brien F, Flynn K, Casey PG, Munoz JA, Kearney $B$ et al (2011) Functional genome analysis of Bifidobacterium breve UCC2003 reveals type IVb tight adherence (Tad) pili as an essential and conserved host-colonization factor. Proc Natl Acad Sci USA 108:11217-11222. https://doi.org/10.1073/pnas.1105380108
101. Ardita C, Mercante J, Kwon YM, Jones R, Powel D, Neish A (2014) Pilin SpaC mediated epithelial adhesion is required for Lactobacillus rhamnosus GG-induced probiotic effects. FASEB 28:60-69. https://doi.org/10.1096/fasebj.28.1.60.9

102. Hiippala K, Jouhten H, Ronkainen A et al (2018) The potential of gut commensals in reinforcing intestinal barrier function and alleviating inflammation. Nutrients 10:988. https://doi.org/10. 3390/nu10080988

103. Porter NT, Canales P, Peterson DA, Martens EC (2017) A subset of polysaccharide capsules in the human symbiont Bacteroides the taiotaomicron promote increased competitive fitness in the mouse gut. Cell Host Microbe 22:494-506. https://doi.org/10. 1016/j.chom.2017.08.020

104. Thakur BK, Dasgupta N, Ta A, Das S (2016) Physiological TLR5 expression in the intestine is regulated by differential DNA binding of $\mathrm{Sp} 1 / \mathrm{Sp} 3$ through simultaneous Sp1dephosphorylation and Sp3 phosphorylation by two different PKC isoforms. Nucleic Acids Res 44:5658-5672. https://doi.org/10.1093/nar/gkw189

105. Gabriele L, Fragale A, Romagnoli G et al (2021) Type I IFNdependent antibody response at the basis of sex dimorphism in the outcome of COVID-19. Cytokine Growth factor Rev 58:6674. https://doi.org/10.1016/j.cytogfr.2020.10.001

106. Sundararaman A, Ray M, Ravindra PV, Halami PM (2020) Role of probiotics to combat viral infections with emphasis on COVID-19. Appl Microbiol Biotechnol 104:8089-8104. https:// doi.org/10.1007/s00253-020-10832-4

107. Gheblawi M, Wang K, Viveiros A, Nguyen Q, Zhong JC et al (2020) Angiotensin-converting enzyme 2: SARS-CoV-2 receptor and regulator of the renin-angiotensin system: celebrating the 20th anniversary of the discovery of ACE2. Circ Res 126:14561474. https://doi.org/10.1161/CIRCRESAHA.120.317015

108. Poggi A, Benelli R, Vene R, Costa D, Ferrari N, Tosetti F, Zocchi MR (2019) Human gut-associated natural killer cells in health and disease. Front Immunol 10:961. https://doi.org/10.3389/ fimmu.2019.00961

109. Hammer AM, Morris NL, Cannon AR, Khan OM, Gagnon RC, Movtchan RV et al (2017) Interleukin-22 prevents microbial dysbiosis and promotes intestinal barrier regeneration following acute injury. Shock 48:657-665. https://doi.org/10.1097/SHK. 0000000000000900

110. Donati Zeppa S, Agostini D, Piccoli G, Stocchi V, Sestili P (2020) Gut microbiota status in COVID-19: an unrecognized player? Front Cell Infect Microbiol 10:576551. https://doi.org/ 10.3389/fcimb.2020.576551

111. Amoroso C, Perillo F, Strati F, Fantini M, Caprioli F, Facciotti $\mathrm{F}$ (2020) The role of gut microbiota biomodulators on mucosal immunity and intestinal inflammation. Cells 9:1234. https://doi. org/10.3390/cells9051234

112. Chairatana P, Nolan EM (2017) Defensins, lectins, mucins, and secretory immunoglobulin A: microbe-binding biomolecules that contribute to mucosal immunity in the human gut. Crit Rev Biochem Mol Biol 52:45-56. https://doi.org/10.1080/10409238. 2016.1243654

113. Priyadarshini M, Kotlo KU, Dudeja PK, Layden BT (2018) Role of short chain fatty acid receptors in intestinal physiology and pathophysiology. Compr Physiol 8:1091-1115. https://doi.org/ 10.1002/cphy.c170050

114. Mustafa MI, Abdelmoneim AH, Mahmoud EM, Makhawi AM (2020) Cytokine storm in COVID-19 patients, its impact on organs and potential treatment by QTY code-designed detergentfree chemokine receptors. Mediators Inflamm 2020:8198963. https://doi.org/10.1155/2020/8198963

115. Corthésy B (2013) Multi-faceted functions of secretory IgA at mucosal surfaces. Front Immunol 4:185. https://doi.org/10.3389/ fimmu.2013.00185 
116. Azad MAK, Sarkar M, Wan D (2018) Immunomodulatroy efets of probiotics on cytokine profiles. Biomed Res Int 2018:8063647. https://doi.org/10.1155/2018/8063647

117. Rocha-Ramírez LM, Pérez-Solano RA, Castañón-Alonso SL, Moreno Guerrero SS, Ramírez PA, García GAM, Eslava C (2017) Probiotic Lactobacillus strains stimulate the inflammatory response and activate human macrophages. J Immunol Res 2017:4607491. https://doi.org/10.1155/2017/4607491

118. Xiao S, Luo D, Xiao Y (2020) Survivors of COVID-19 are at high risk of posttraumatic stress disorder. Glob Health Res Policy 5:29. https://doi.org/10.1186/s41256-020-00155-2

119. Ahlawat S, Asha SKK (2020a) Immunological co-ordination between gut and lungs in SARS-CoV-2 infection. Virus Res 286:198103. https://doi.org/10.1016/j.virusres.2020.198103

120. Ahlawat S, Asha SKK (2020b) Gut-organ axis: a microbial outreach and networking. Lett Appl Microbiol 72:636-668. https:// doi.org/10.1111/lam.13333

121. Carabotti M, Scirocco A, Maselli MA, Severi C (2015) The gutbrain axis: interactions between enteric microbiota, central and enteric nervous systems. Ann Gastroenterol 29:240

122. Appleton $\mathbf{J}$ (2018) The gut-brain axis: influence of microbiota on mood and mental health. Integr Med 17:28-32

123. Bravo JA, Forsythe P, Chew MV, Escaravage E, Savignac HM, Dinan TG, Bienenstock J, Cryan JF (2011) Ingestion of Lactobacillus strain regulates emotional behavior and central GABA receptor expression in a mouse via the vagus nerve. Proc Natl Acad Sci USA 108:16050-16055. https://doi.org/10.1073/pnas. 1102999108

124. Flik G, Folgering JH, Cremers TI, Westerink BH, Dremencov E (2015) Interaction between brain histamine and serotonin, norepinephrine, and dopamine systems: invivo microdialysis and electrophysiology study. J Mol Neurosci 56:320-328. https://doi. org/10.1007/s12031-015-0536-3

125. Gebremariam HG, Qazi KR, Somiah T, Pathak SK, Sjölinder H, Sverremark Ekström E, Jonsson AB (2019) Lactobacillus gasseri suppresses the production of proinflammatory cytokines in Helicobacter pylori-infected macrophages by inhibiting the expression of ADAM17. Front Immunol 10:2326. https://doi. org/10.3389/fimmu.2019.02326

126. Yong SJ, Tong T, Chew J, Lim WL (2020) Anti-depressive mechanisms of probiotics and their therapeutic potential. Front Neurosci 13:1361. https://doi.org/10.3389/fnins.2019.01361

127. Nalbandian A, Sehgal K, Gupta A, Madhavan MV, McGroder C, Stevens JS, Cook JR, Nordvig AS, Shalev D, Sehrawat TS, Ahluwalia N et al (2021) Post-acute COVID-19 syndrome. Nat Med 27:601-615. https://doi.org/10.1038/s41591-021-01283-z

128. Lai CC, Wang CY, Hsueh PR (2020) Co-infections among patients with COVID- the need for combination therapy with non-anti-SARS-CoV-2 agents? J Microbiol Immunol Infect 53:505-512. https://doi.org/10.1016/j.jmii.2020.05.013

129. Salehi M, Ahmadikia K, Badali H, Khodavaisy S (2020) Opportunistic fungal infections in the epidemic area of COVID-19: a clinical and diagnostic perspective from Iran. Mycopathologia 185:607-611. https://doi.org/10.1007/s11046-020-00472-7

130. Sarkar S, Gokhle T, Choudhury SS, Deb AK (2021) COVID-19 and orbital mucromycosis. Indian J Ophthalmol 69:1002-1004. https://doi.org/10.4103/ijo.IJO376320

131. Razemb B, Dennaib Y, Slimania F (2021) Chronical rhino-orbital mucormycosis in an immunocompetent host: a case report. Int $\mathbf{J}$ Surg Case Rep 82:105882. https://doi.org/10.1016/j.ijscr.2021. 105882

132. Lv L, Gu S, Jiang H, Yan R, Chen Y, Chen Y, Luo R, Huang C et al (2021) Gut mycobiota alterations in patients with COVID-19 and H1N1 infections and their associations with clinical features. Commun Biol 4:480. https://doi.org/10.1038/ s42003-021-02036-x

133. Matsubara VH, Bandara HMHN, Mayer MPA, Samaranayake LP (2016) Probiotics as antifungals in mucosal candidiasis. Clin Infect Dis 62:1143-1153. https://doi.org/10.1093/cid/ciw038

134. Rossoni RD, de Barros PP, Mendonça IC, Medina RP, Silva DHS, Fuchs BB, Junqueira JC, Mylonakis E (2020) The postbiotic activity of Lactobacillus paracasei 28.4 against Candida auris. Front Cell Infect Microbiol 10:397. https://doi.org/10. 3389/fcimb.2020.00397

135. Murzyn A, Krasowska A, Stefanowicz P, Dziadkowiec D, Lukaszewicz M (2010) Capric acid secreted by S. boulardii inhibits $C$. albicans filamentous growth, adhesion and biofilm formation. PLoS One 5:e12050. https://doi.org/10.1371/journal. pone. 0012050

136. Veiga P, Suez J, Derrien M, Elinav E (2020) Moving from probiotics to precision probiotics. Nat Microbiol 5:878-880. https:// doi.org/10.1038/s41564-020-0721-1

137. Qu K, Guo F, Liu X, Lin Y, Zou Q (2019) Application of machine learning in microbiology. Front Microbiol 10:827. https://doi. org/10.3389/fmicb.2019.00827

138. Aryal S, Alimadadi A, Manandhar I, Joe B, Cheng X (2020) Machine learning strategy for gut microbiome-based diagnostic screening of cardiovascular disease. Hypertension 10:15561561. https://doi.org/10.1161/hypertensionaha.120.15885

139. Westfall S, Carracci F, Estill M, Zhao D, Wu Q, Shen L, Simon J, Pasinetti GM (2021) Optimization of probiotic therapeutics using machine learning in an artificial human gastrointestinal tract. Sci Rep 11:1067. https://doi.org/10.1038/s41598-020-79947-y

140. Scheiman J, Luber JM, Chavkin TA, MacDonald T, Tung A, Pham L, Wibowo MC, Wurth RC, Punthambaker S, Tierney BT, Yang Z et al (2019) Meta-omic analysis of elite athletes identifies a performance-enhancing microbe that functions via lactate metabolism. Nat Med 25:1104-1109. https://doi.org/10.1038/ s41591-019-0485-4

Publisher's Note Springer Nature remains neutral with regard to jurisdictional claims in published maps and institutional affiliations. 